\title{
Emetic Reflex Arc Revealed by Expression of the Immediate-early Gene c-fos in the Cat
}

\author{
Alan D. Miller ${ }^{1}$ and David A. Ruggiero ${ }^{2,3}$ \\ ${ }^{1}$ Rockefeller University, and ${ }^{2}$ Department of Neurology, Cornell University Medical Center, New York, New York 10021, \\ and ${ }^{3}$ the Neurological Research Institute of Lubec, Lubec, Maine 04652
}

The organization of the central neuronal circuitry that produces vomiting was explored by mapping the distribution of c-fos protein (Fos)-like immunoreactivity (FLI) as a monitor of functional activity. The brainstem and spinal cord were examined in cats administered multiple emetic drugs (cisplatin, lobeline, protoveratrine, naloxone, apomorphine) or control saline injections. Some animals were decerebrated, paralyzed, and artificially ventilated to avoid possible Fos expression induced by sensory feedback or fluid depletion during vomiting. Fictive vomiting was identified in these animals by a characteristic pattern of respiratory muscle nerve (phrenic and abdominal) coactivation. Tissues were immunoprocessed using an antibody raised against amino acids 1-131 of Fos and the avidin-biotin peroxidase complex method. Enhanced nuclear FLI was observed in experimental animals along portions of the sensorimotor emetic reflex arc, including the nodose ganglia, area postrema, nuclei of the solitary tract (especially medial and subpostrema subnuclei), intermediate reticular zone of the lateral tegmental field, nucleus retroambiguus, $\mathrm{C}_{2}$ inspiratory propriospinal cell region, and dorsal vagal and phrenic motor nuclei. Enhanced $\mathrm{FLI}$ was also detected in the raphe magnus, subretrofacial nucleus, and spinal dorsal horn. Regions showing no recognizable differences in FLI between experimental and control animals included the vestibular, cochlear, spinal trigeminal, subtrigeminal, and lateral reticular nuclei. Only minor differences were observed in the distributions of FLI between intact and decerebrate animals. No unique, welldefined group of labeled neurons that might function as a "vomiting center" could be identified. Instead, the pattern of $\mathrm{c}$-fos expression suggests that neurons involved in coordinating the emetic response may radiate from the area postrema and nucleus of the solitary tract to an arc in the lateral tegmental field implicated in somato-autonomic integration.

[Key words: emesis, vomiting, c-fos, Fos, area postrema, nucleus of the solitary tract, lateral tegmental field, cisplatin, emetic drug action, brainstem, spinal cord, central pattern generators]

Received Mar. 31, 1993; revised July 29, 1993; accepted Aug. 12, 1993.

This work was supported by grants NS20585 (A.D.M.) and NS28200 (D.A.R.) from the National Institute of Neurological Disorders and Stroke. We thank Dr. Tom Curran (Roche Institute of Molecular Biology, Nutley, NJ) for providing the antiserum to Fos.

Correspondence should be addressed to Dr. Alan D. Miller, The Rockefeller University, 1230 York Avenue, New York, NY 10021.

Copyright (C) 1994 Society for Neuroscience 0270-6474/94/140871-18\$05.00/0
Nausea and vomiting (emesis) are precipitated by diverse stimuli, yet their neural substrates remain incompletely understood (Davis et al., 1986b; Carpenter, 1989; Kucharczyk et al., 1991; Bianchi et al., 1992). The activity-driven expression of c-fos protein (Fos) has been used as a monitor of functional activation of second- and higher-order neurons in several systems (e.g., Sagar et al., 1988; Dragunow and Faull, 1989; Bullitt, 1990; Erickson and Millhorn, 1991; Wan et al., 1992). c-fos is an immediate-early gene that is rapidly expressed in response to ncuronal activation. After bcing synthesized in the cytoplasm, Fos is rapidly translocated to the nucleus where, with the Jun protein, it forms a heterodimer that regulates the expression of other genes (e.g., Morgan and Curran, 1989, 1991; Sheng and Greenberg, 1990). Thus, Fos is a marker of functional activity, with resolution at the level of the single cell nucleus, that afforded a means of investigating the neuronal circuitry generating vomiting.

We examined the central expression of Fos-like immunoreactivity (FLI) induced by vomiting in cats. Possible Fos activation due to fluid or electrolyte imbalance or to sensory feedback during the motor act of vomiting was avoided by monitoring Fos induction following "fictive vomiting" in decerebrate, paralyzed animals (Miller et al., 1987). Lesion studies have demonstrated that the critical circuits for coordinating vomiting are located within the medulla caudal to the facial nucleus (Fukuda

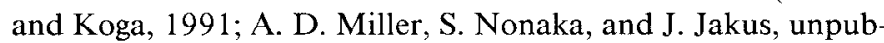
lished observations). We therefore focused our attention on this region of the brainstem as well as on selected spinal segments that harbor respiratory and autonomic motoneurons.

A preliminary report of this work has been presented (Miller and Ruggiero, 1992).

\section{Materials and Methods}

Experimental design. Experiments were carried out on six adult cats. Three cats were treated with a combination of emetic drugs whereas three control animals were administered saline instead of emetic drugs. Data were obtained from one pair of experimental and control animals that did not undergo any surgical intervention other than intraperitoneal injections. Experiments were carried out in two other pairs of cats that were decerebrated, paralyzed, and artificially ventilated. In these animals, we measured the occurrence of fictive vomiting rather than actual vomiting. Fictive vomiting was identified by a characteristic series of bursts of coactivation of diaphragmatic (phrenic) and abdominal motor nerves that would produce retching and expulsion in nonparalyzed animals (Miller et al., 1987). Pairs of drug-treated and control animals were run in parallel on the samc days. These experiments were approved by the Institutional Animal Care and Use Committee.

Surgical procedures. Decerebration was performed on four animals under halothane (Fluothane, Ayerst)-nitrous oxide anesthesia, which was discontinued following the completion of all surgical procedures. 

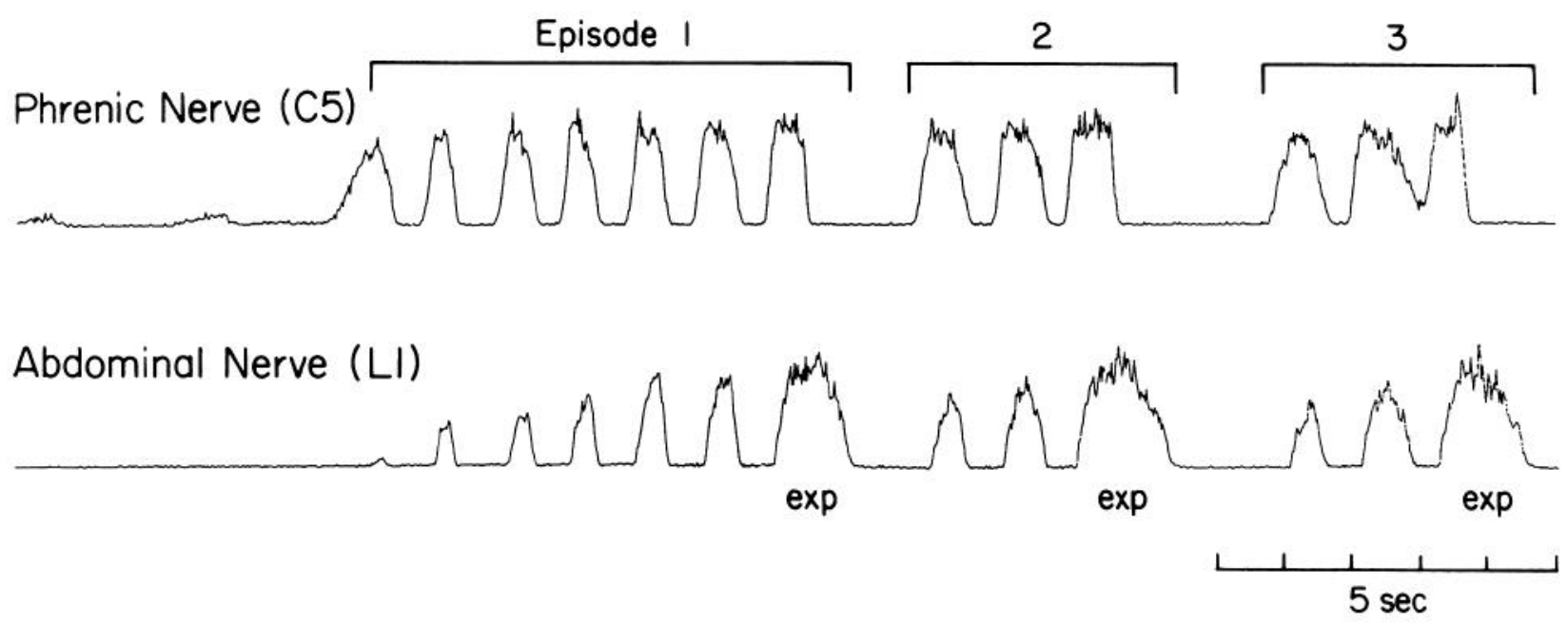

Figure 1. Phrenic and abdominal nerve discharges are illustrated during respiration and (fictive) vomiting. The two motor nerves, which are active during different phases of respiration, are coactivated during vomiting. Each emetic episode consists of several bursts of nerve discharge and typically terminates with an expulsion (exp) phase that is characterized by prolonged abdominal discharge. Shown are three episodes of fictive vomiting, consisting of 13 bursts of nerve coactivation. Note that nerve discharge increases during fictive vomiting in comparison to respiration.
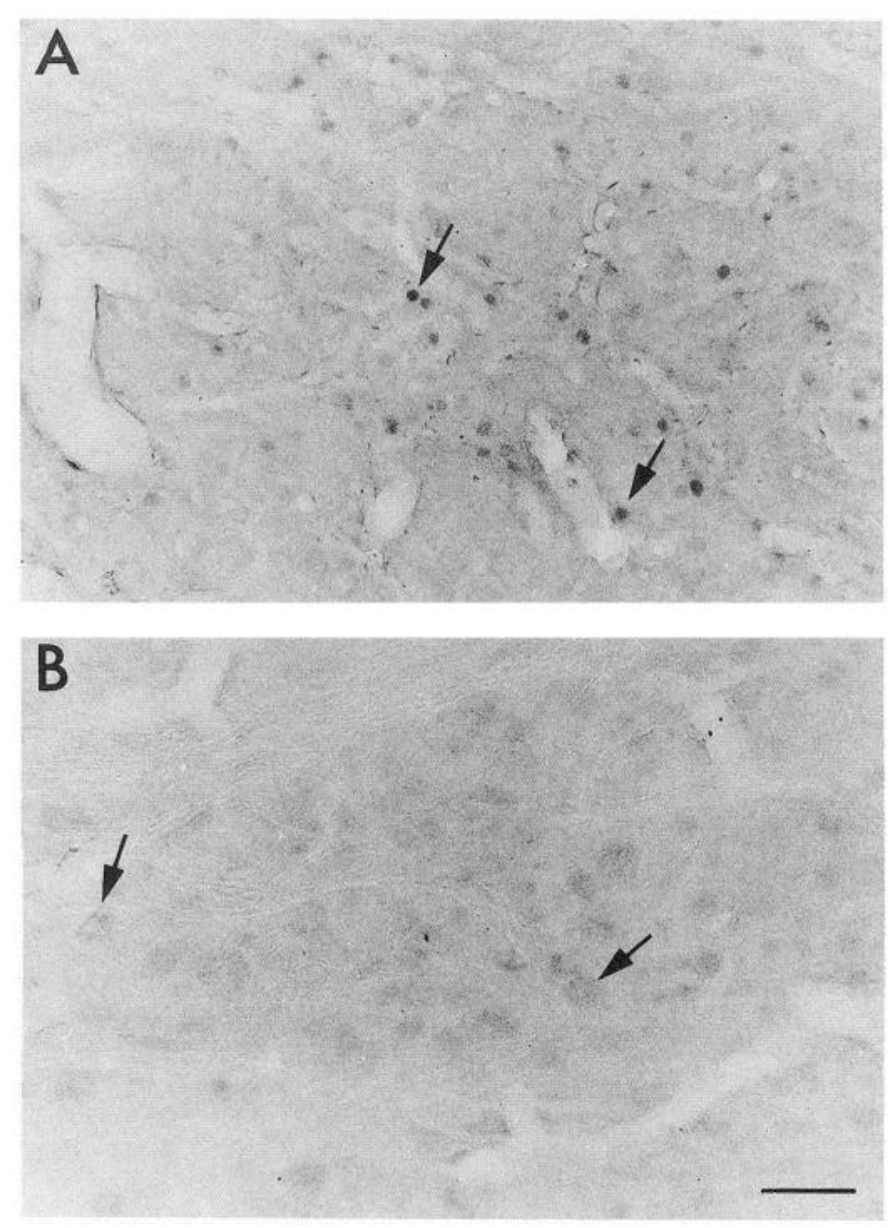

Figure 2. Photomicrographs of the nodose ganglia are shown from an experimental $(A)$ and control $(B)$ animal. Arrows in $A$ indicate Fos-like immunopositive nuclei, whereas neurons in the control ganglion (arrows in $B$ ) do not express FLI. Data in this and all following figures are from intact animals. Scale bar, $100 \mu \mathrm{m}$.
The trachea was intubated, and cannulas placed in the femoral artery to monitor blood pressure and in the femoral veins for drug administration. The animals were temporarily placed in a stereotaxic frame. Intercollicular decerebration was performed after bilateral ligation of the carotid arteries. Bipolar cuff recording electrodes were attached to the central ends of the cut $\mathrm{C} 5$ phrenic and $\mathrm{L} 1$ abdominal muscle nerves (Miller et al., 1987). The animals were then removed from the stereotaxic apparatus, in an effort to minimize sensory inputs, and placed on their side. Rectal temperature was kept at $36-37^{\circ} \mathrm{C}$ using a heating lamp. The animals were paralyzed with gallamine triethiodide (Flaxedil, Davis + Geck) and artificially ventilated with room air ( 24 cycles/min). Endtidal $\mathrm{CO}_{2}$ was maintained between 4-6\%. Phrenic and abdominal muscle nerve activities were amplified, full-wave rectified, low-pass filtered with a $10 \mathrm{msec}$ time constant, and recorded on line at a sampling rate of $100 \mathrm{~Hz}$ using a PDP $11 / 23$ computer (Digital Equipment Corp.).

Administration of emetic drugs. Vomiting was produced in one nonoperated cat and fictive vomiting was produced in two decerebrate, paralyzed animals using a combination of emetic drugs in an attempt to produce a large number of emetic episodes within a circumscribed time period and thus increase the likelihood of inducing Fos expression along an extensive portion of the emetic reflex arc. Animals were given a single injection of cisplatin $[10 \mathrm{mg} / \mathrm{kg}$, i.p., cis-platinum (11) diammine dichloride; Sigma], and then, starting an hour later, multiple (four to six) injections of a combination of drugs were administered intraperitoneally to the nonoperated animal and intravenously to the decerebrate animals. A typical injection consisted of $1-2 \mathrm{mg} / \mathrm{kg}$ apomorphine hydrochloride (Lilly), $0.5-1 \mathrm{mg} / \mathrm{kg}$ lobeline sulfate (Sigma), 1-2 $\mathrm{mg} / \mathrm{kg}$ naloxone hydrochloride (Sigma), and 5-10 $\mu \mathrm{g} / \mathrm{kg}$ protoveratrine (Sigma). Control animals received comparable volumes of saline administered over a similar injection schedule. Animals were continuously monitored to ensure that they showed no signs of distress. Animals were killed 5.5-6.5 hr after receiving cisplatin and 4-5 hr after the onset of vomiting or fictive vomiting. Times of death corresponded to $7-8 \mathrm{hr}$ following decerebration.

Tissue processing. Animals were deeply anesthetized with sodium pentobarbital (Nembutal, Abbott; $40 \mathrm{mg} / \mathrm{kg}$, i.p., or $25 \mathrm{mg} / \mathrm{kg}$, i.v.) and perfused transcardially with saline followed by $4 \%$ paraformaldehyde in $0.1 \mathrm{M}$ phosphate buffer, $\mathrm{pH}$ 7.4. The brainstem, spinal cord segments at $\mathrm{C} 2, \mathrm{C} 5, \mathrm{~T} 1-\mathrm{T} 2, \mathrm{~T} 7$, and L1-L2, and nodose ganglia were removed and blocked. Identical procedures were followed in control and experimental animals. The blocks of tissue were postfixed for $2-3 \mathrm{hr}$ in individual vials containing $4 \%$ paraformaldehyde in $0.1 \mathrm{~m}$ phosphate

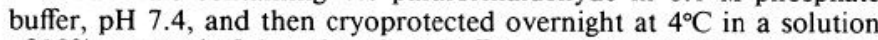
of $10 \%$ sucrose in $0.1 \mathrm{~m}$ phosphate buffer, $\mathrm{pH} 7.4$. Frozen sections were cut at $35 \mu \mathrm{m}$ in the transverse plane using a sliding (sledge) microtome. Every fourth section from the brainstem and several sections from the 

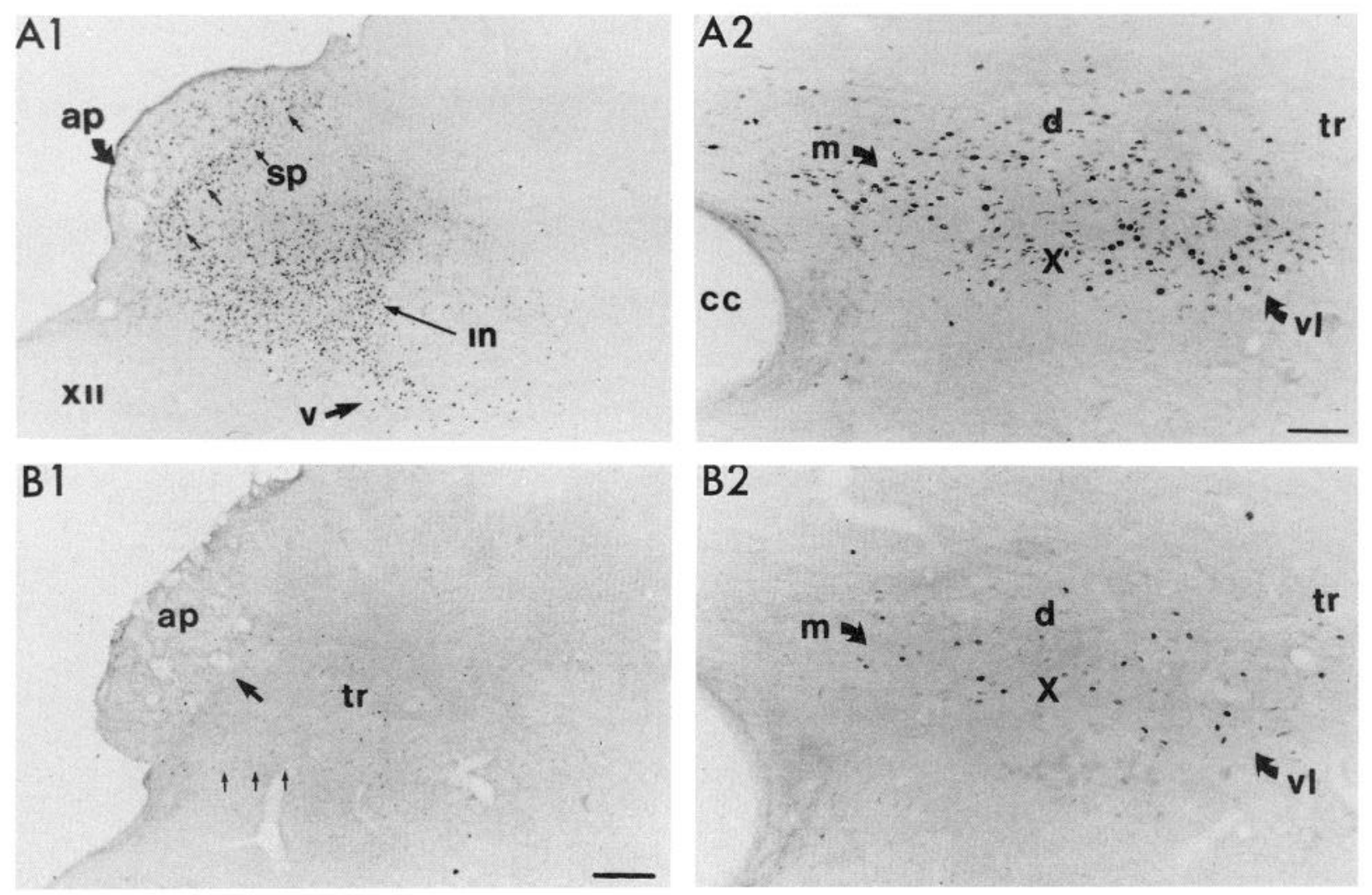

Figure 3. Photomicrographs from an experimental $(A 1, A 2)$ and control $(B 1, B 2)$ animal of transverse sections of the AP and NTS at levels rostral $(A 1, B 1)$ and caudal $(A 2, B 2)$ to the obex. $A 1$, Dramatic increases in FLI occurred in experimental animals in the area postrema (ap), nucleus subpostrema ( $s p$, small arrows), and ventral $(v)$ and intermediate $(i n)$ subnuclei bordering the solitary tract (tr). Hypoglossal nucleus is indicated by $X I I$. A2, FLI induction in contiguous loci of caudal commissural division of NTS including medial $(m)$, dorsal $(d)$, and ventrolateral $(v l)$ subnuclei, and in the dorsomotor vagal nucleus $(X)$. A few labeled nuclei surround the central canal $(c c)$. $B 1$ and $B 2$, Note sparse labeling of similar loci in NTS-AP on tissues from a control animal. The three small arrows in $B 1$ point to the dorsomotor vagal nucleus. Scale bars: $A 1$ and $B 1,250$ $\mu \mathrm{m} ; A 2$ and $B 2,100 \mu \mathrm{m}$.

nodose ganglia and spinal cord were processed immunocytochemically for c-fos protein. Tissues from control and experimental animals were processed simultaneously in separate test wells. The histologist was unaware of which tissues were from drug-treated versus control animals. All incubations were carried out on a Thomas rotator table. Tissues were collected in $0.1 \mathrm{M}$ phosphate-buffered saline (PBS) ( $\mathrm{pH} 7.4$ ) in spot test wells and washed in Tris-buffered saline (TBS) between each step. Before incubating in the antiserum, nonspecific binding sites were blocked by preincubating for $30 \mathrm{~min}$ in goat serum, diluted 1:30 in TBS. Thereafter, sections were incubated in primary whole rabbit antiserum raised against amino acids $1-131$ of Fos (generously donated by Dr. T. Curran, Roche Institute of Molecular Biology, Nutley, NJ). The antibody is relatively specific for Fos and does not seem to recognize any of the known Fos-related proteins (T. Curran, personal communication). Its biochemical properties have been described (Cohen and Curran, 1990). The antiserum was diluted $1: 10,000$ in TBS, containing $1 \%$ goat serum, to which $0.2 \%$ Triton $\mathrm{X}-100$ was added to facilitate tissue penetration. All tissues were incubated for $3 \mathrm{~d}$ in a cold room at $4^{\circ} \mathrm{C}$. Finally, tissues were incubated in biotinylated goat anti-rabbit $\mathrm{IgG}$ secondary antibody $(1: 200,30-45 \mathrm{~min})$ and avidin-biotin peroxidase complex $(1: 100,60$ min) (Vector Labs, Elite kit 6001). The bound peroxidase immunoreaction product was visualized by treating tissues with a $0.05 \%$ substrate solution of the chromogen diaminobenzidine and $0.01 \% \mathrm{H}_{2} \mathrm{O}_{2}$ in TBS. Some sections from both drug-treated and control animals were processed omitting incubation in primary antibody. Sections were washed, mounted, dehydrated, cleared, and coverslipped without counterstaining.

Data analysis. Data were analyzed with a Leitz or Zeiss microscope, plotted with a drawing tube, and photographed using Kodak Tmax 100 film. Nomenclature used follows that of Taber et al. (1960) for the raphe nuclei, Loewy and Burton (1978) and Kalia and Mesulam (1980) for the subnuclei of the solitary tract, Berman (1968) for the rest of the brainstem, and Rexed (1954) for the spinal cord.

\section{Results}

Production of emesis

In two decerebrate, paralyzed preparations, totals of 143 and 159 episodes of fictive vomiting were produced over $3-4 \mathrm{hr}$. Each emetic episode consisted of 2-12 bursts of coactivation of phrenic and abdominal muscle nerve activity (Fig. 1), for totals of 571 and 609 bursts of nerve coactivation, respectively, for the two animals. In the nonoperated animal, 97 episodes of vomiting, consisting of a total of 509 bursts of muscle cocontraction, were visually observed over $3.5 \mathrm{hr}$. No vomiting or fictive vomiting occurred in control animals given saline injections.

\section{Expression of FLI}

Neurons expressing FLI exhibited wide variations in intensity of nuclear immunoreaction product, ranging from almost black to pale brown yet distinct from background. FLI was observed in both experimental and control animals; however, all drugtreated animals exhibited dramatic increases in both the intensity of nuclear FLI and the number of immunolabeled nuclei as compared to controls. No FLI was observed on histological sections incubated in the absence of primary antibody to Fos. 

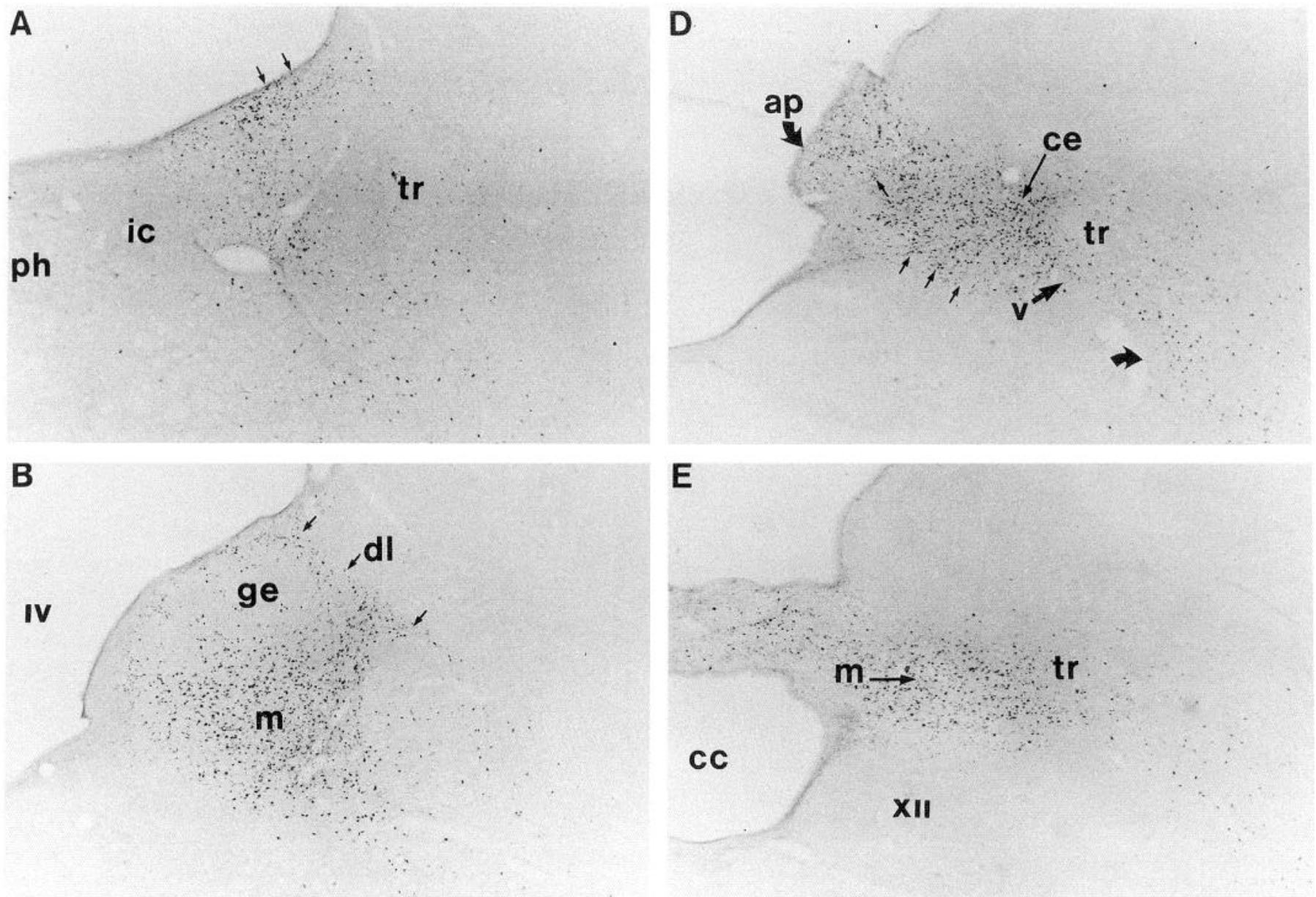

C
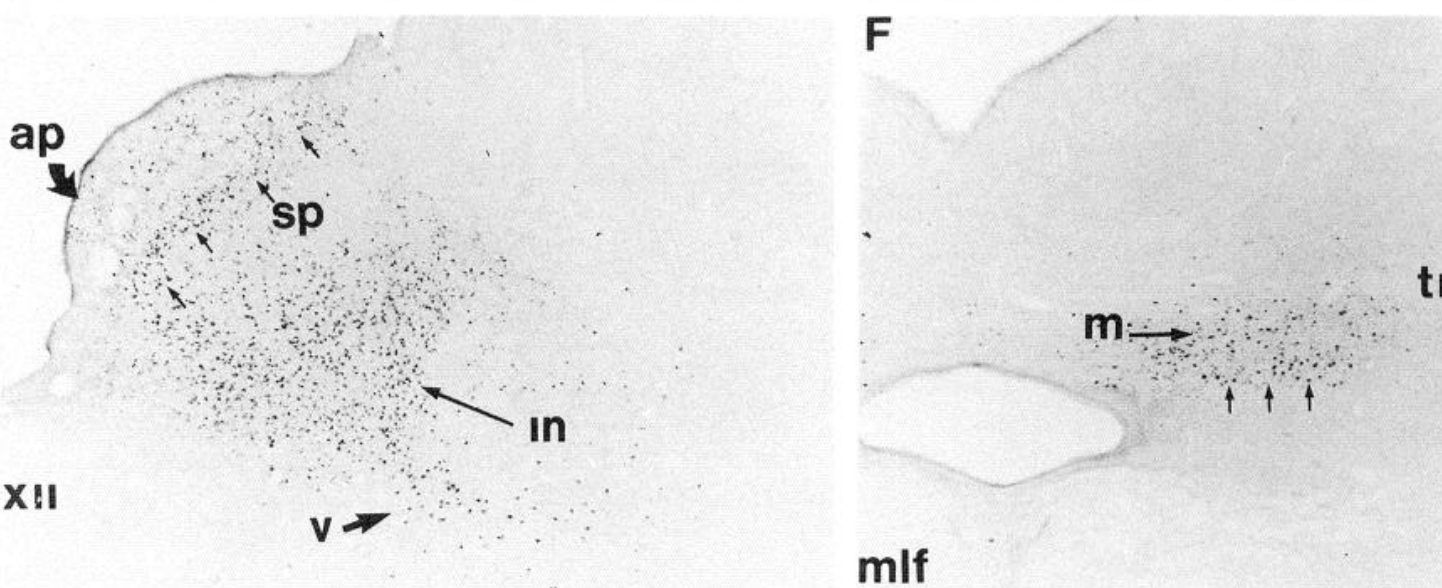

Figure 4. Photomicrographs from an experimental animal illustrating the distribution of FLI from rostral $(A)$ to caudal $(F)$ levels of the NTS. Note the subnucleus gelatinosus $(g e)$ was unlabeled $(B, C)$. Small arrows point to FLI in the periventricular gray $(A)$, dorsolateral $(d l)$ subnucleus $(B)$, nucleus subpostrema $(C, D)$, and the ventral border of the dorsal motor nucleus $(D, F)$. Curved arrows in $D$ and $F$ point to transitional area between the ventral $(v)$ division of NTS and the intermediate reticular zone. $c e$, central subnucleus of the NTS; $i c$, nucleus intercalatus; $m l f$, medial longitudinal fasciculus; $p h$, nucleus prepositus hypoglossi; $i v$, fourth ventricle. Other abbreviations are as in Figure 3 . Bar equals $250 \mu \mathrm{m}$.

Figure 5. Camera lucida drawings of transverse sections at three levels of the medulla comparing FLI in an experimental $(A I-C I)$ versus control $(A 2-C 2)$ animal. Fos-like immunopositive neurons were densely distributed in discrete nuclei of the NTS and in organized columns radially arranged in the lateral tegmental field $(L T F)$. See Results for details. Arrow in $A 1$ points to subretrofacial nucleus. $C X$, external cuneate nucleus; $D M X$, dorsal motor nucleus of the vagus; $I O$, inferior olive; $I V N$, inferior vestibular nucleus; $L R N$, lateral reticular nucleus (l, lateral division; $m$, medial division); $M A O$, medial accessory olive; $M V N$, medial vestibular nucleus; $N A$, nucleus ambiguus; $N C$, cuneate nucleus; $N G$, gracilis nucleus; $N G C$, nucleus gigantocellularis; $N T S r$, rostral nucleus tractus solitarius; $P$, pyramidal tract; $R B$, restiform body; $R F$, retrofacial nucleus; $R M$, raphe magnus; $S t$, subtrigeminal nucleus; $S T N$, spinal trigeminal nucleus; $S T T$, spinal trigeminal tract; $X$, subnucleus $\mathrm{X}$ of IVN. Other abbreviations are as in previous figures. 

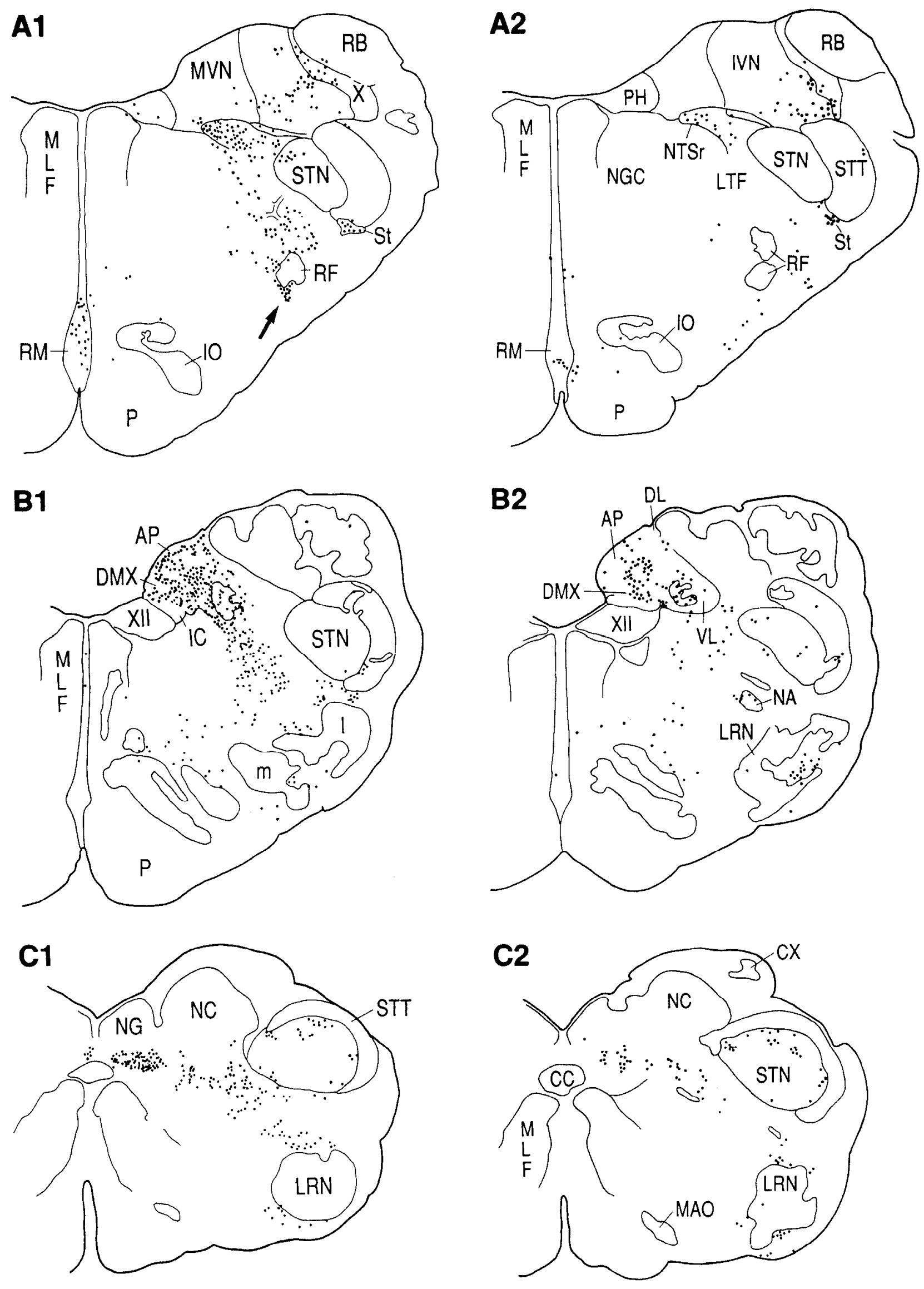
Similar distributions of FLI were observed in intact and decerebrate animals, with minor exceptions noted below. All of the following illustrations are from the two nonoperated animals.

\section{Distribution of FLI in the brainstem}

Enhanced nuclear expression of FLI was observed in experimental animals along portions of the entire emetic reflex arc, from sensory input sites [nodose ganglia of the vagus nerve (Fig. 2), nucleus of the solitary tract (NTS), area postrema (AP) (Figs. 3-6)] to premotor internuncial [retroambiguus (Figs. $5 \mathrm{Cl}, 6 \mathrm{H}-$ $J, 7 D)$ ] and motor [dorsal vagal (Figs. 3-6), phrenic (see Figs. $9 b 1,10)$ ] nuclei. Neurons were intensely labeled and densely distributed within discrete nuclei of the solitary tract and along radial sheets extending diagonally across the intermediate zone of the lateral tegmental field (LTF) to the ventrolateral medulla (VLM) (Figs. 5, 6).

The dramatic increases in FLI in the NTS in an experimental versus control animal are demonstrated in the photomicrographs in Figure 3. Enhanced nuclear expression of FLI was observed in discrete subnuclei extending from the rostrally located orosensory nucleus to the commissural division near the spinomedullary junction (Fig. 4). Prominently labeled regions included the rostral-lateral gustatory nucleus, the medial division ("m" in Figs. $3 A$ ?, $4 B-F$ ) including the medial parvocellular nucleus and, at levels bordering the obex, the subpostremal ("sp," Figs. 3A1, 4C) and central subnuclei ("ce," Fig. 4D). Immunoreactive nuclei in the nucleus subpostrema formed a diagonal sheet in an area transitional with the AP. On some sections, arrays of immunolabeled nuclei extended dorsomedially into the AP and ventrolaterally into the subjacent part of the medial division of the NTS. The nucleus subpostrema was distinguished from a prominent unlabeled cell column corresponding to the subnucleus gelatinosus ("ge," Fig. 4B), which is located midway between the solitary tract and the dorsal medullary surface. The subnucleus centralis was heavily labeled and composed of a compact core of FLI-labeled neurons surrounded by a larger sphere of immunostained neurons having a lower packing density. The intermediate subnucleus ("in," Figs. $3 A 1,4 C$ ), which lines the medial convexity of the solitary tract, contained a moderate density of neurons expressing FLI. Fewer and less intensely labeled neurons were found in the area dorsal and dorsomedial to the solitary tract corresponding to the dorsal-lateral division (Figs. $3 A 2,4 B$ ). A sparse although well-circumscribed collection of labeled neurons occurred in proximity to the ventral border of the solitary tract within the ventral division (ventral and ventrolateral subnuclei, Figs. $3 A 1, A 2 ; 4 C-F)$. The majority of these labeled nuclei were seen at caudal and intermediate levels of the NTS in a region transitional with the dorsal LTF. Few labeled neurons were observed in the region immediately lateral to the solitary tract (lateral subnucleus). The nucleus parvocellularis compactus (nucleus parasolitarius), which is intercalated between the dorsal and lateral subnuclei and the nucleus gracilis, or at rostral levels the medial vestibular nucleus, was also devoid of immunoreactive nuclei. At levels caudal to the obex, FLI was induced in the commissural division of the NTS (Figs. $3 A 2,4 E, F$ ).

In the reticular formation, a large percentage of nuclei activated in animals that exhibited an emetic response were located in the intermediate reticular zone of the LTF. The labeling from an experimental and control animal is compared at three levels of the medulla in Figure 5, while the detailed distribution of labeling induced in an experimental animal is illustrated at several medullary levels in Figure 6. In control animals, those few neurons that expressed FLI in the intermediate reticular nucleus and VLM contained low densities of immunoreaction product. In experimental animals, labeled neurons formed oblong or irregularly shaped longitudinal columns that extended parallel to the neuraxis from the upper cervical spinal gray to the facial nucleus. Bridges of labeled neurons interconnected the columns. A large number of neurons were also labeled in the pontine LTF. However, at levels rostral to the facial nucleus, the sheets of labeled cells were interrupted and not as well circumscribed. Many immunoreactive neurons in the LTF were aligned with perforating blood vessels (Figs. 6, 7B) (cf. King, 1980; King and Knox, 1984)

Prominent immunolabeling was observed in the dorsal LTF subjacent to the NTS, as illustrated in Figure $7 \mathrm{~A}$. Branches of intensely labeled nuclei extended diagonally and bidirectionally from this column toward the NTS and ventrolateral reticular formation. Other distinct cell columns were recognized by enhanced nuclear FLI relative to control data. One was the subretrofacial nucleus, a small compact column of intensely labeled neurons in the rostral ventrolateral reticular formation subjacent to the facial and retrofacial nuclei (diagonal arrows in Figs. $5 A 1$, $6 B-D, 7 C$ ). Another was the rostral para-ambigual complex, a larger ovoid column of nuclei having a lower packing density than the subretrofacial nucleus (horizontal arrows in Fig. $6 B, C$ ). At the level depicted in Figure $6 D$, the two columns of immunopositive cells werc contiguous. At lcvels caudal to the obex, immunoreactive neurons were observed in the nucleus retroambiguus (Figs. $6 H-J, 7 D$ ).

Small numbers of immunoreactive nuclei were identified in the nucleus raphe magnus and parapyramidal region, where the densities of labeled neurons were higher in experimental than control animals (Figs. 5A, 6A-C).

In other brainstem regions, no recognizable differences were observed between experimental and control groups in the number or intensity of immunolabeled nuclei. These regions include the subtrigeminal (Fig. 8) (cf. McAllen et al., 1992), spinal trigeminal, vestibular, cochlear, and lateral reticular nuclei, and the pontine periventricular gray matter.

In comparison with other control animals, one of the two

Figure 6. Camera lucida drawings of transverse sections through different rostrocaudal levels of the medulla oblongata illustrating patterns of immunocytochemical nuclear expression of FLI in an experimental animal. Low- and high-magnification plots are shown for each level. More celis with weak to moderately labeled nuclei were observed and plotted using high magnification than shown in drawings made from low magnification. Expression of FLI was induced in neurons of the NTS, intermediate zone of the LTF, AP, and DMX. In the NTS, immunolabeled neurons were concentrated in the rostral $(A-D)$, dorsolateral, medial, parvicellular, central, and subpostremal nuclei $(E-G)$, and caudal commissural divisions $(H-J)$. In the reticular formation, labeling occurred in the $L T F$ subjacent to the NTS. Immunolabeled neurons also formed columns corresponding to the subretrofacial $(B-D$, diagonal arrows), para-ambigual $(B-C$, horizontal arrows), and retroambiguus $(H-J)$ nuclei. $C N X$, commissural nucleus of the vagus; $D A O$, dorsal accessory olive; $D C$, dorsal cochlear nucleus; $I S$, interstitialis subnucleus; $P I O$, principal inferior olive; $P R$, paramedian reticular formation; $P Z$, pars zonale of $S I N ; R A$, retroambiguus nucleus; $R P a$, raphe pallidus; $v$, blood vessel; $V M S$, ventral medullary surface; $V I I$, facial nucleus. Other abbreviations are as in previous figures. 

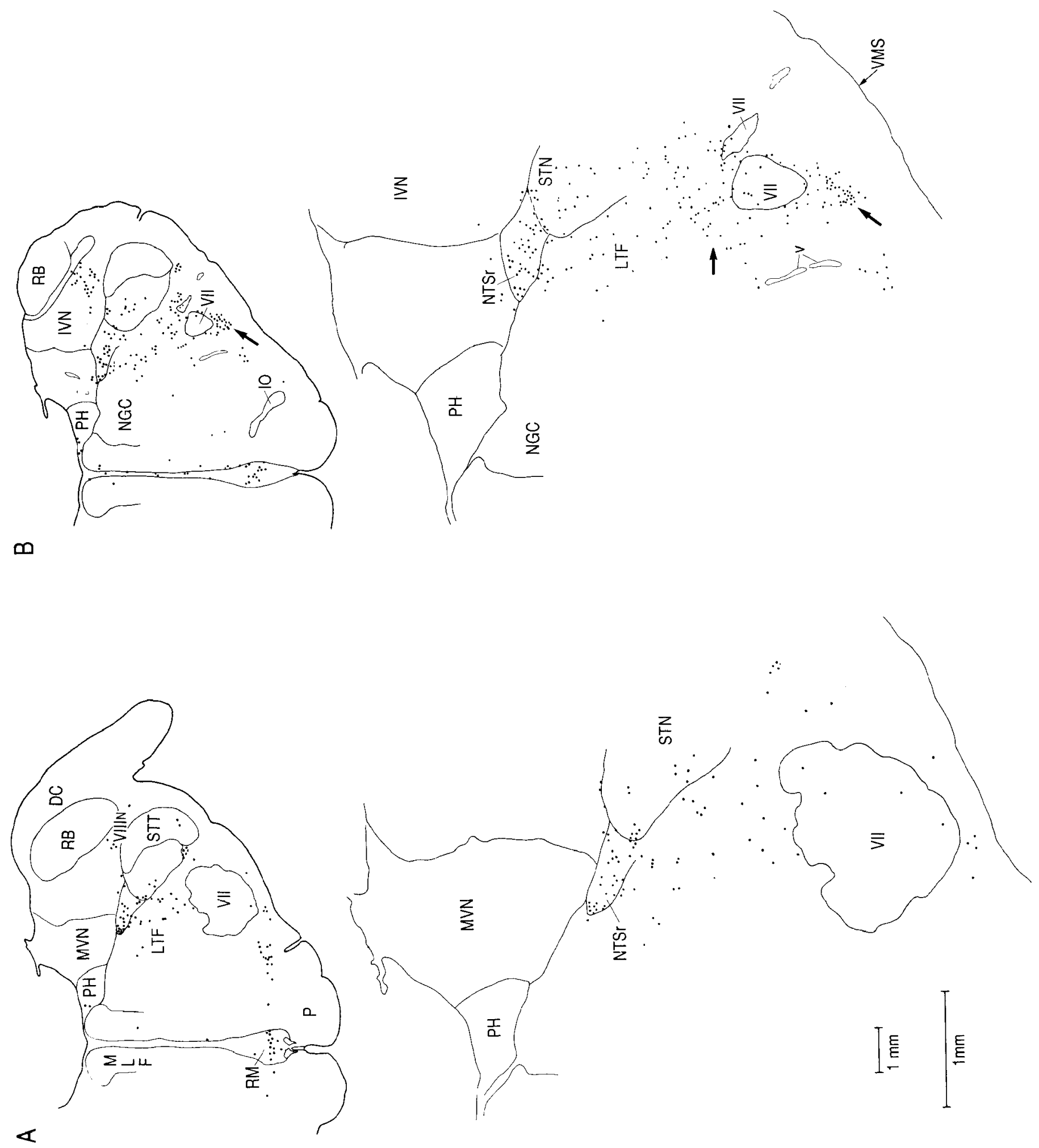

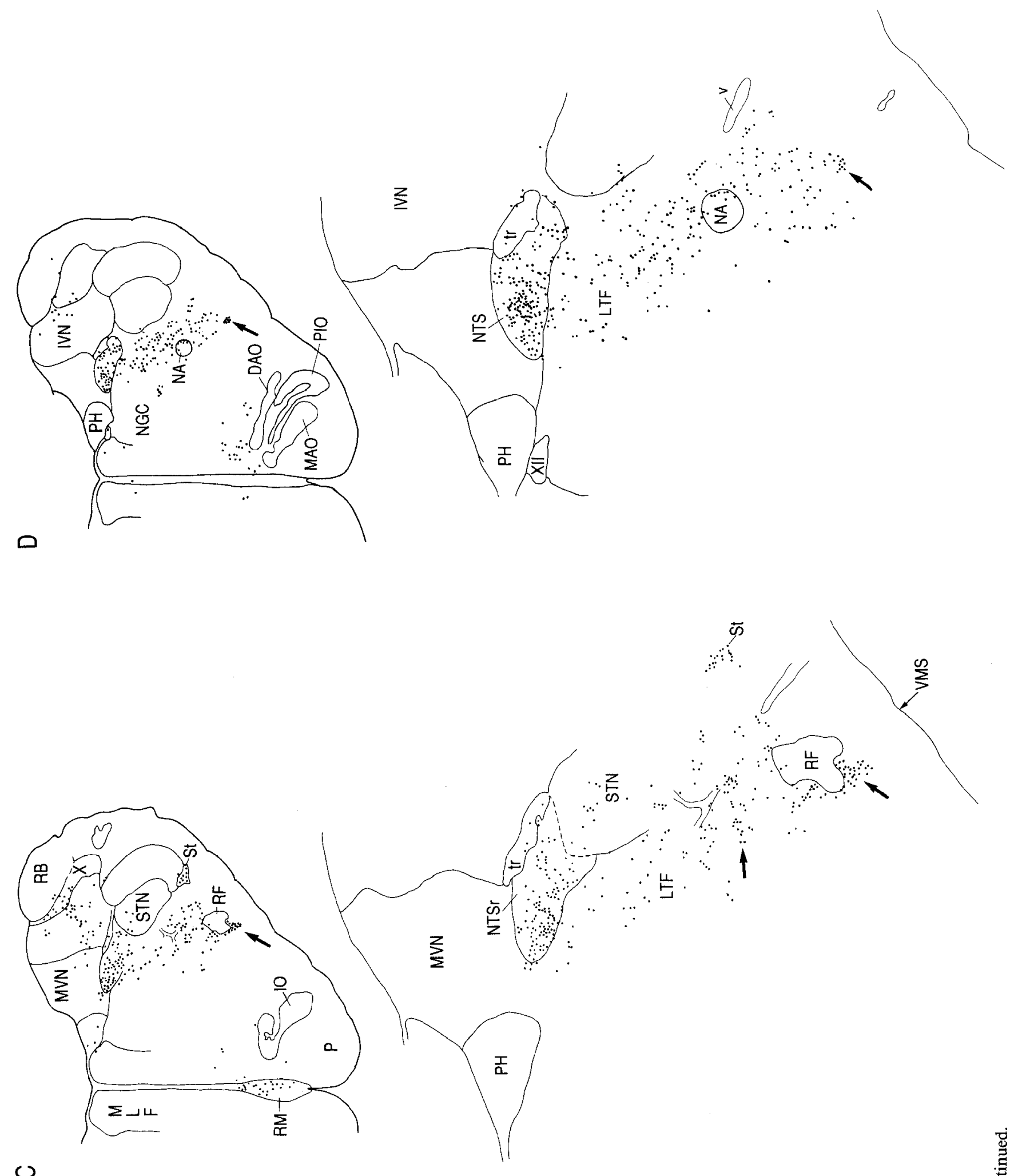


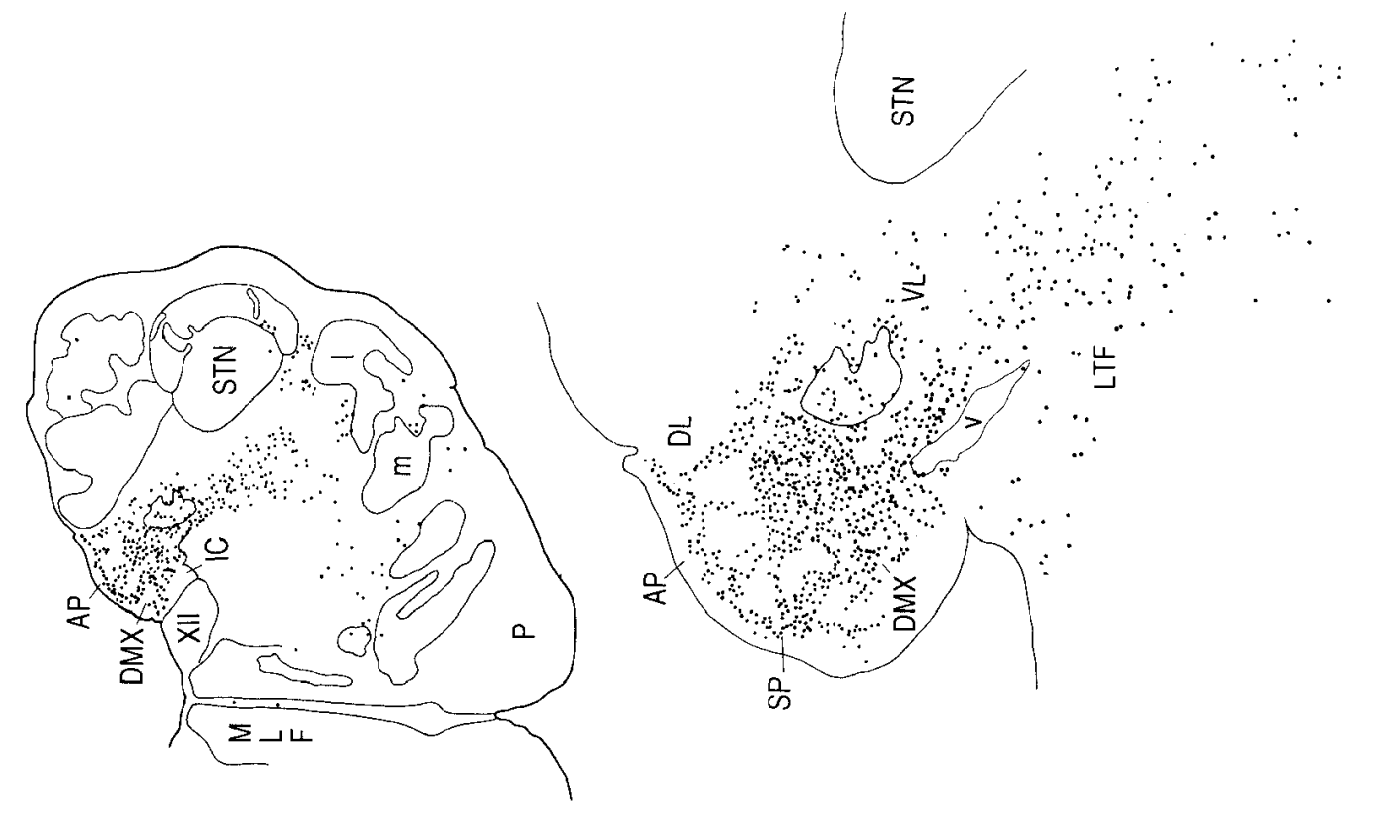

ᄂ

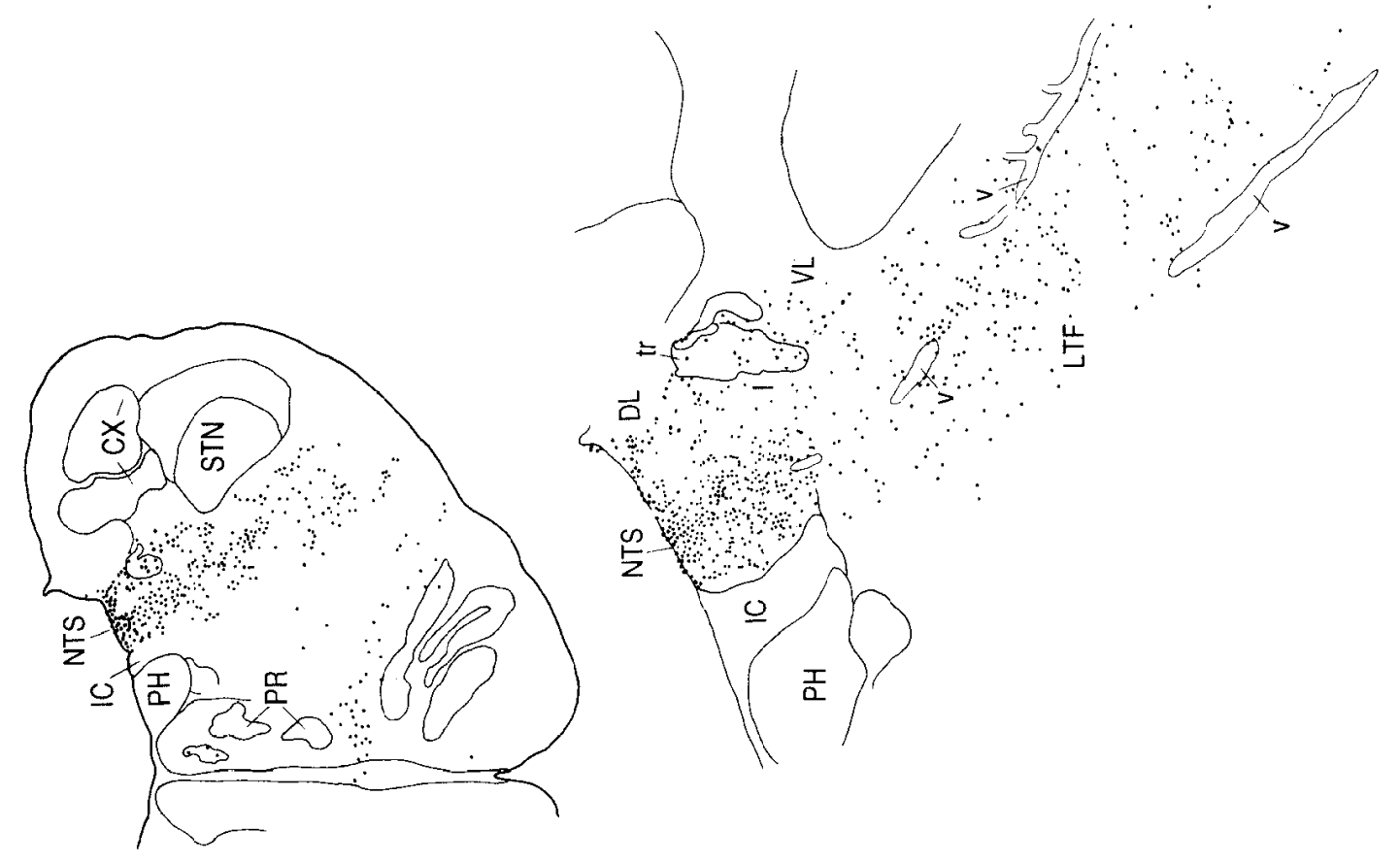

ш 

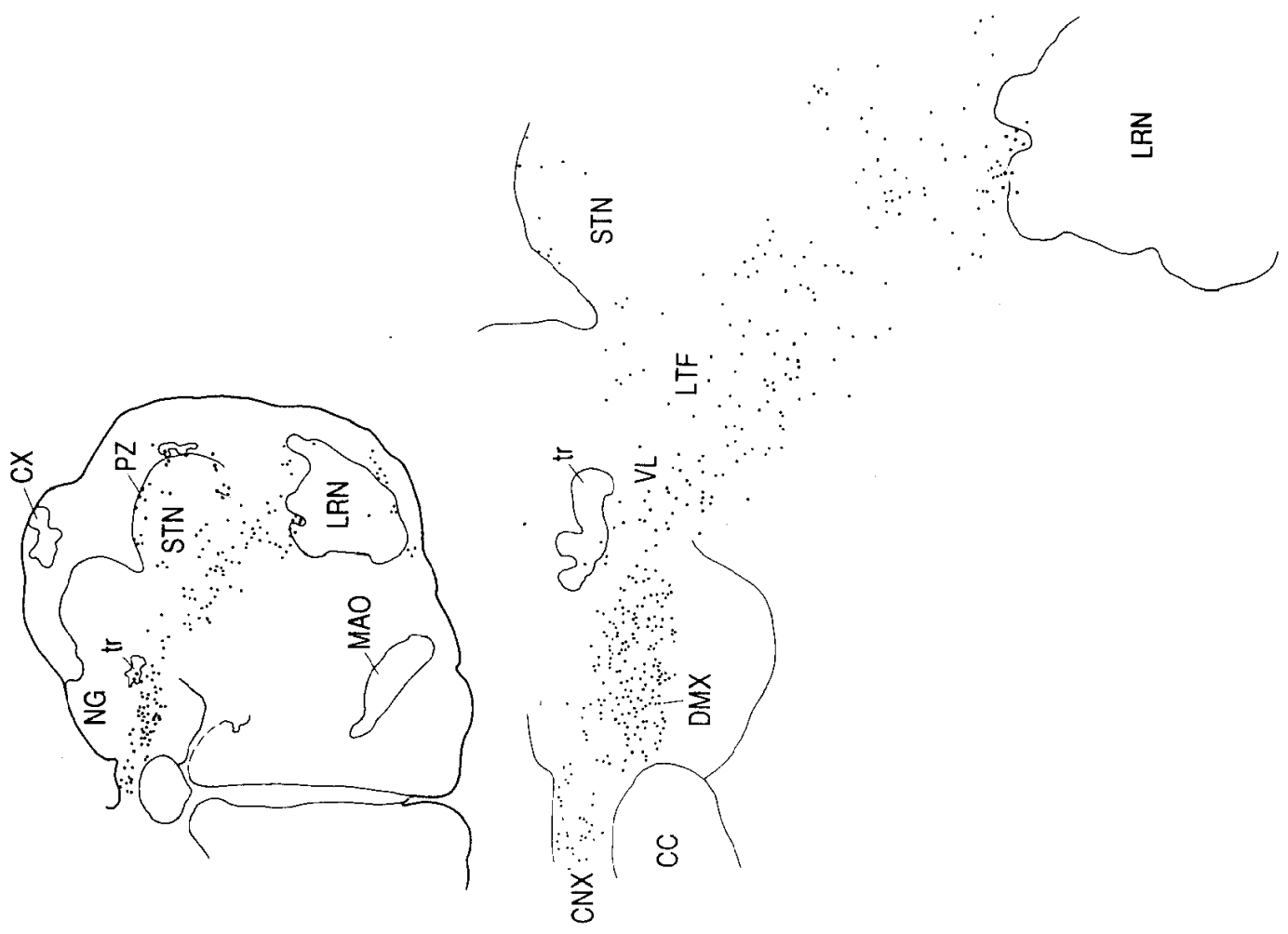

$I$

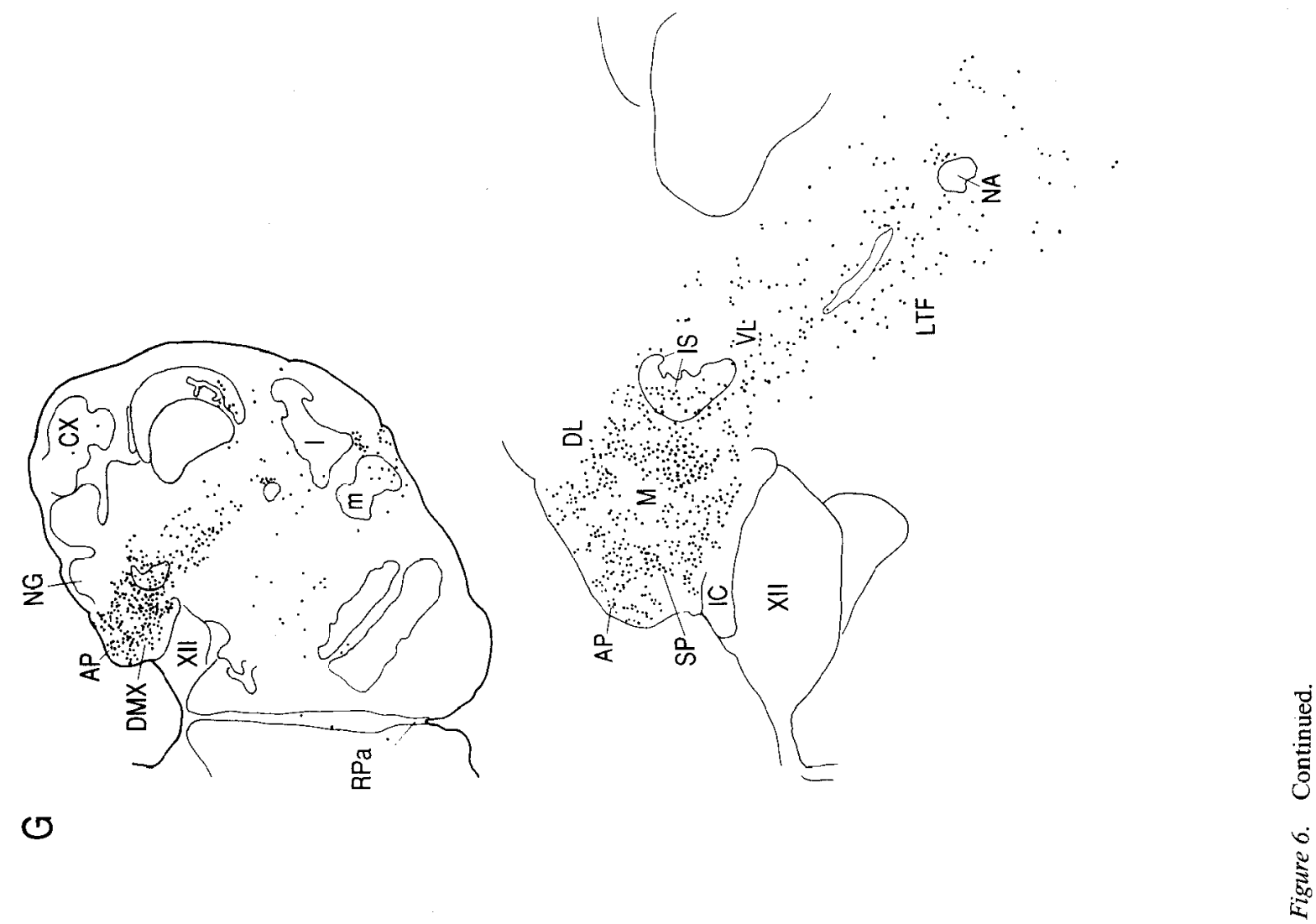



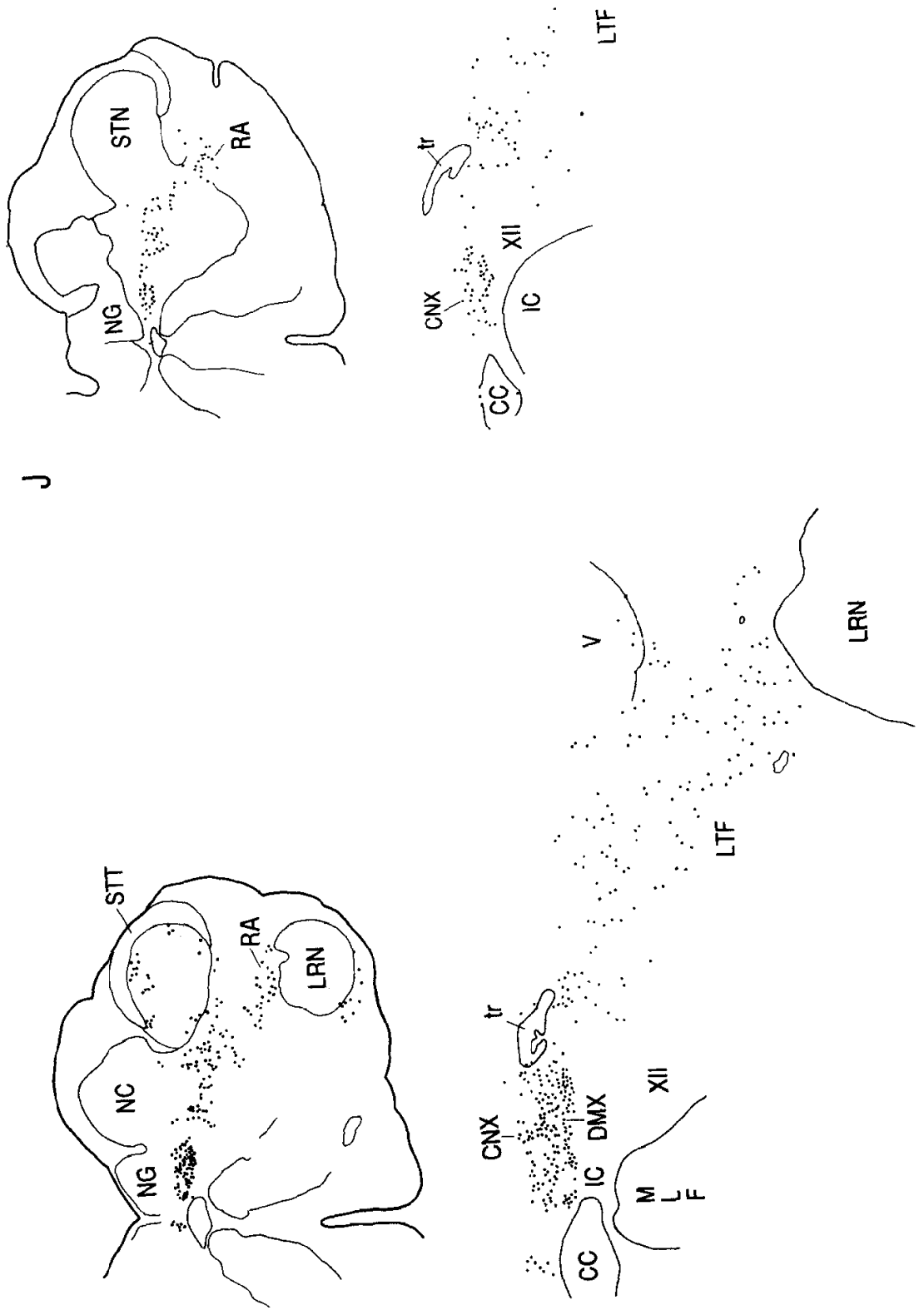
decerebrate controls exhibited enhanced FLI in the subretrofacial nucleus and in the dorsolateral subnucleus of the NTS, which is a termination site of baroreceptor afferents (Kumada et al., 1990).

\section{Distribution of FLI in the spinal cord}

In the spinal cord (Fig. 9), labeled neurons were observed in experimental animals in the region of the upper cervical inspiratory propriospinal cell column (C2) and the phrenic motor nucleus (C5) (Fig. 10). Enhanced FLI was also observed in experimental animals in laminae V and VII of cervical and thoracic segments and in superficial laminae of the dorsal horn, especially laminae II-III. Scattered labeling was also seen in laminae I, IV, and VIII, although clear-cut and consistent differences between experimental and control groups could not be demonstrated. A few labeled neurons were also observed in the intermediolateral cell column, lamina X, and intercostal and/ or abdominal motor pools in the ventral horn.

\section{Differences in FLI distribution between intact and decerebrate animals}

Decerebrate animals exhibited greater FLI than intact animals in three regions: the dorsal accessory olive, the dorsal part of the medial and inferior vestibular nuclei, and the raphe pallidus. There were no obvious differences in labeling in these regions between decerebrate experimental versus control animals.

\section{Discussion}

Induction of Fos was observed in animals that exhibited emetic episodes along portions of the emetic reflex arc, from sites of primary sensory input (nodose ganglia, NTS, AP) to premotor (nucleus retroambiguus) and motor (dorsal vagus, phrenic nuclei) output limbs. Since the only variable distinguishing experimental from control cases was the systemic administration of emetic drugs versus saline, we conclude that the identified cell groups were related to reflexes activated by the drugs. The patterns of FLI in the medulla were strongly suggestive that the drug regimes induced Fos expression among neurons involved in the emetic reflex response. Indeed, a close correspondence was noted between Fos-positive nuclei and cell groups known to subserve functionally different components of emesis. For example, consistent with activation of respiratory-related neurons critical for vomiting (Miller, 1992), enhanced FLI was observed in experimental animals in regions that include propriobulbar and expiratory bulbospinal neurons in the Bötzinger and related para-ambigual regions of the rostral ventral respi-
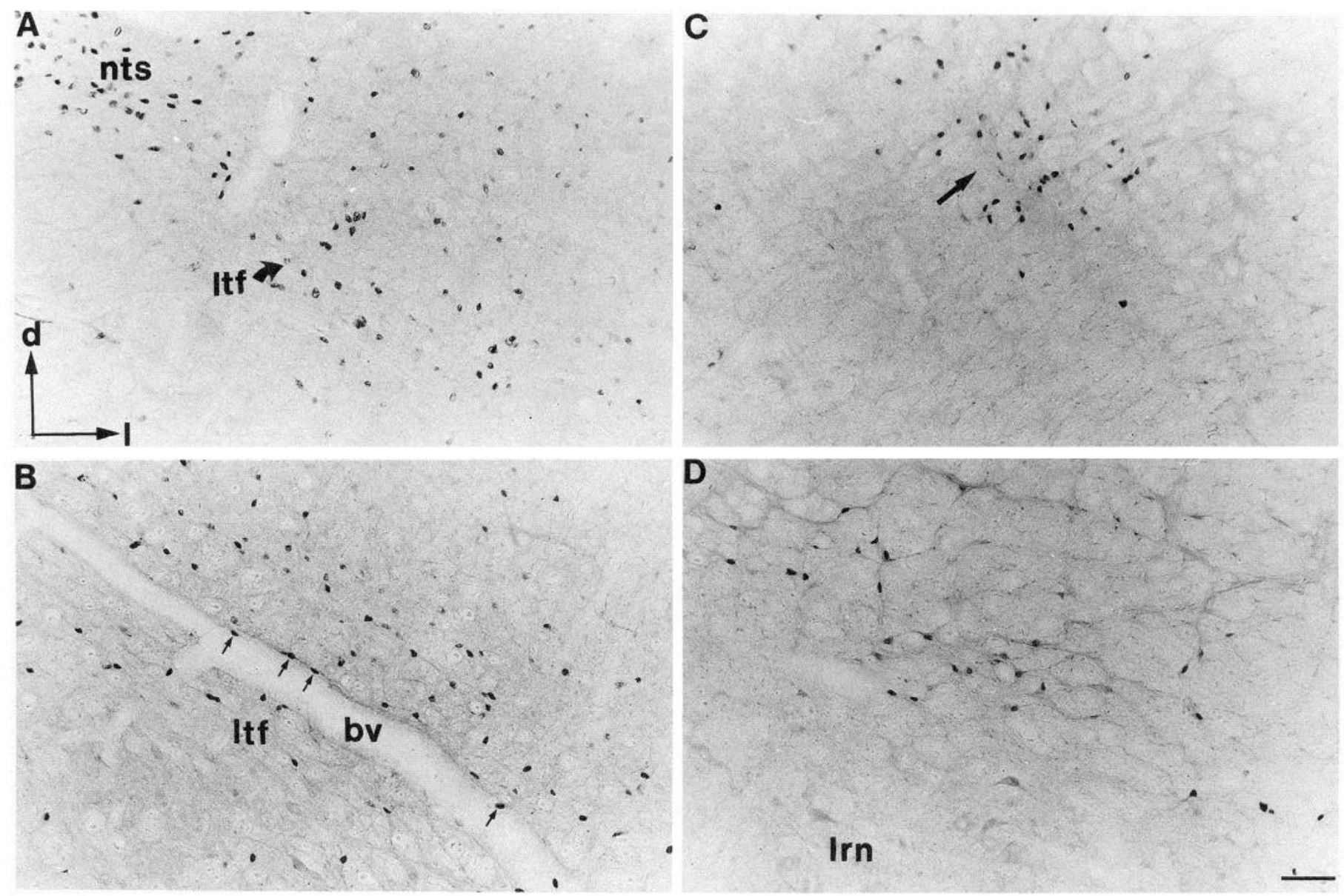

Figure 7. Fos-like immunopositive neurons in the nucleus tractus solitarius ( $n t s)$ and subnuclei of the lateral tegmental field (ltf) in an experimental animal. $A$, Immunolabeled neurons in the ventrolateral subnucleus of NTS and in a subjacent (parasolitary) column of the dorsal LTF. Arrows indicate dorsal $(d)$ and lateral $(l)$ directions and apply to all photomicrographs in this figure. $B$, Bands of immunolabeled nuclei in the LTF rostral to the obex. The neurons radiate diagonally across the reticular formation and are arranged in parallel with the long axis of a perforating blood vessel $(b v)$. Arrows indicate labeled nuclei in proximity to the wall of the vessel. $C$, Subretrofacial column (arrow) in the rostral VLM subjacent to the retrofacial nucleus. $D$, Nucleus retroambiguus in the caudal VLM dorsal to the lateral reticular nucleus $(l r n)$. Scale bar, $100 \mu \mathrm{m}$. 

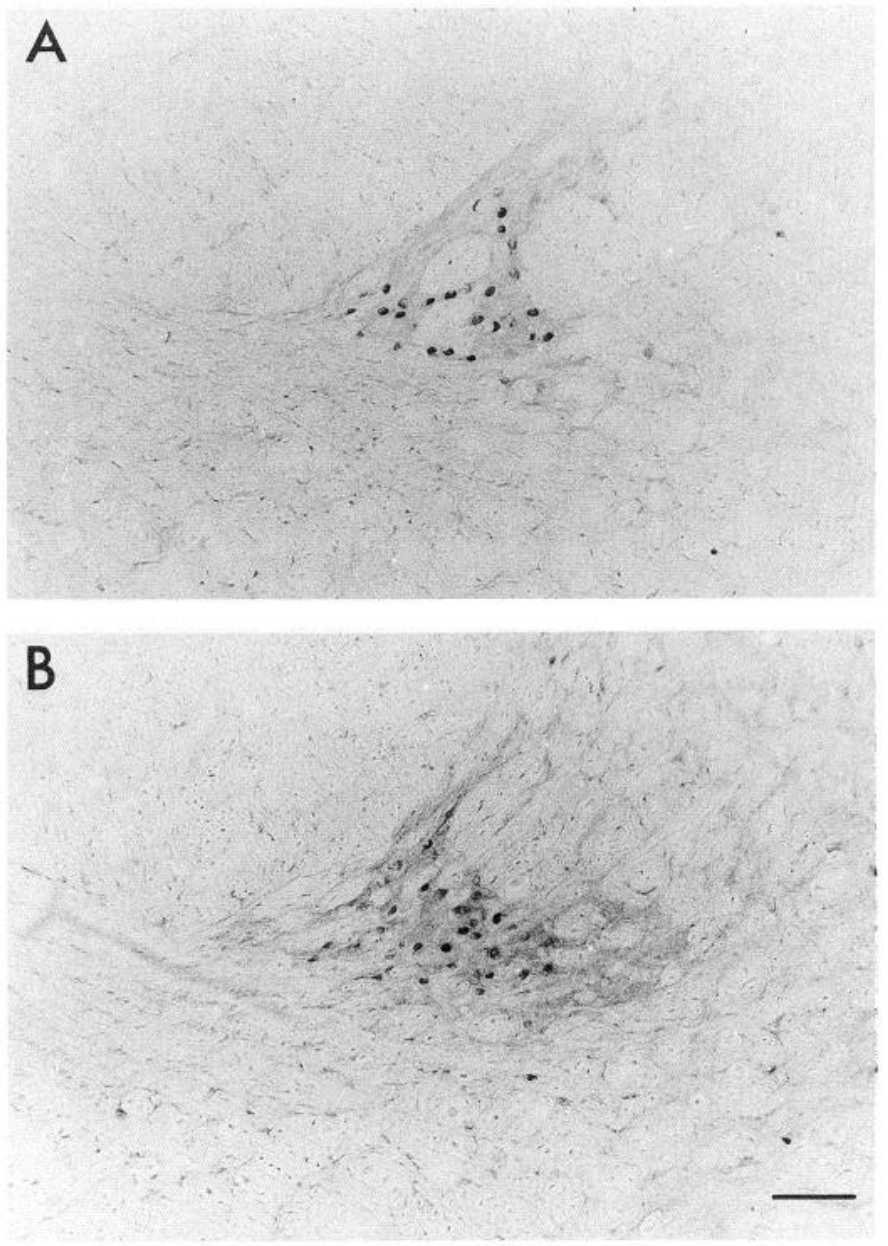

Figure 8. Photomicrographs illustrating FLI in the subtrigeminal nucleus in experimental $(A)$ and control $(B)$ animals. No differences were observed in either the density of labeled neurons or in the intensity of immunolabeled nuclei. Scale bar, $100 \mu \mathrm{m}$.

ratory group (VRG) (Miller and Nonaka, 1990a; Miller and Ezure, 1992), expiratory bulbospinal neurons in the nucleus retroambiguus at levels of the VRG caudal to the obex (Miller et al., 1987; Miller and Nonaka, 1990b), upper cervical (C1C3) inspiratory propriospinal neurons (Nonaka and Miller, 1991), and phrenic motoneurons (e.g., Miller et al., 1987). The nucleus retroambiguus, in addition to providing excitatory drive to spinal respiratory motoneurons, has also been implicated in the control of motoneurons innervating upper airway (Holstege, 1989; Zhang et al., 1992) and pelvic floor (Holstege and Tan, 1987) musculature. In addition, other nuclei activated in experimental animals showed a strong correspondence in spatial distribution to reticulopremotor nuclei engaged in cranial nerve integration (Holstege and Kuypers, 1977; Holstege et al., 1977). The coordinated activation of oropharyngeal and laryngeal motoneurons is an integral component of the vomiting response (Grélot et al., 1990).
Some of the enhanced labeling observed in experimental animals may not be related to the motor act of vomiting. For example, nuclear expression of Fos occurs in the AP and NTS following systemic administration of emetic drugs to the rat, a species that does not vomit (Gu et al., 1991; Leslie and Reynolds, 1992). Labeling in the AP, nodose ganglia, NTS, dorsal motor nucleus of the vagus, and the spinal dorsal horn was an expected response to sensory activation produced by the emetic drugs. Of the drugs used in our experiments, cisplatin produces vomiting by a cascade of mechanisms that probably involve parallel activation of abdominal visceral (vagal and splanchnic) afferents and the emetic chemoreceptor trigger zone in the AP (McCarthy and Borison, 1984; Reynolds et al., 1991; Miller and Nonaka, 1992; Naylor and Rudd, 1992). Protoveratrine acts at the level of the nodose ganglia (Borison and Fairbanks, 1952; Borison and Sampson, 1961), whereas apomorphine acts via the AP (Wang and Borison, 1952), and lobeline-induced vomiting appears to be mediated by a combination of spinal and vagal afferents and the AP (Laffan and Borison, 1957). Naloxone is thought to act centrally although the site of action is unknown (Costello and Borison, 1977).

In the NTS, a close correspondence was observed betwecn the patterns of nuclear expression of FLI and sites of afferent input from the AP (Morest, 1967; van der Kooy and Koda, 1983; Shapiro and Miselis, 1985) and abdominal vagus nerve (Gwyn et al., 1979; Kalia and Mesulam, 1980; Norgren and Smith, 1988). These sites include the subpostremal, medial, and commissural subnuclei. In contrast, the subnucleus gelatinosus was devoid of FLI, an unexpected observation since this region is a principal recipient of gastric afferents (Gwyn et al., 1979; Kalia and Mesulam, 1980; Norgren and Smith, 1988). However, gastric afferents do make monosynaptic connections in the subnucleus gelatinosus with dorsally extending dendrites of dorsal vagal motoneurons (Rinaman et al., 1989), which did express enhanced FLI.

Enhanced FLI has been previously reported in the AP, NTS, and dorsal motor nucleus of the vagus in response to emetic stimuli in the ferret, an animal that like the cat is capable of vomiting (Reynolds et al., 1991; Leslie and Reynolds, 1992). These investigators concentrated their studies on the dorsal vagal complex but did not observe the extensive distribution of enhanced nuclear FLI that was induced in our study. The reasons for this difference are not clear, although there are several possibilities. In the aforementioned studies, a single emetic drug (cisplatin, loperamide, or ipecacuanha) was administered to individual animals, whereas we used a combination of several (cisplatin, apomorphine, naloxone, lobeline, and protoveratrine) in the same animal and produced, on average, fourfold more vomiting (total number of retches plus expulsions) per animal as they did using cisplatin (Reynolds et al., 1991). Our survival periods were $2-3 \mathrm{hr}$ longer, and data were obtained with a different primary antibody. Possible species differences could contribute to the discrepancies. A recent abstract also reported Fos expression in the ferret dorsal vagal complex following electrical stimulation of the supradiaphragmatic vagus

Figure 9. Camera lucida drawings of Fos-like immunopositive neurons in the spinal gray of representative cervical $(C 2, C 5)$, thoracic $(T 2, T 7)$, and upper lumbar (L2) segments. Transverse sections of spinal cord from an experimental (al-e1) and control (a2-e2) animal are shown. Note the increases in FLI-positive nuclei in the experimental animal in laminae V and VII and dorsal horn laminae II-III of most spinal segments, in the upper cervical inspiratory $(U C I)$ cell column (compare al to a2), phrenic motor nucleus (arrow, compare $b 1$ to $b 2$ ), and thoracolumbar intermediolateral $(I L)$ and intermediomedial $(I M)$ cell columns (compare $c 1-e 1$ to $c 2-e 2$ ). 
EXPERIMENTAL

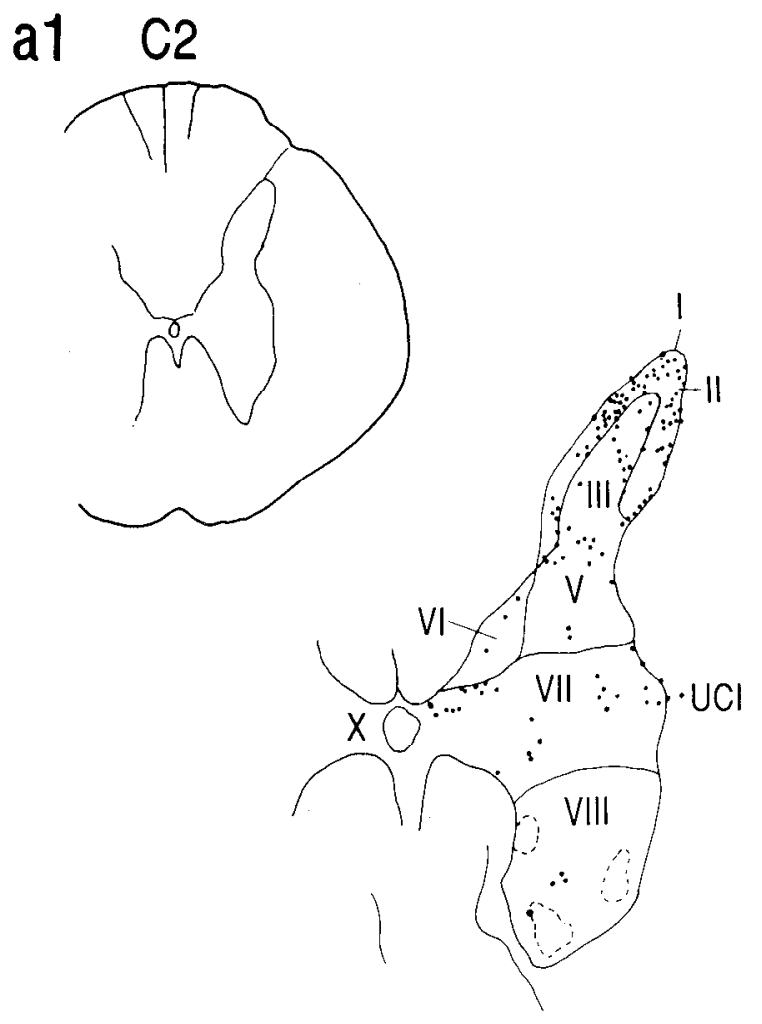

Control

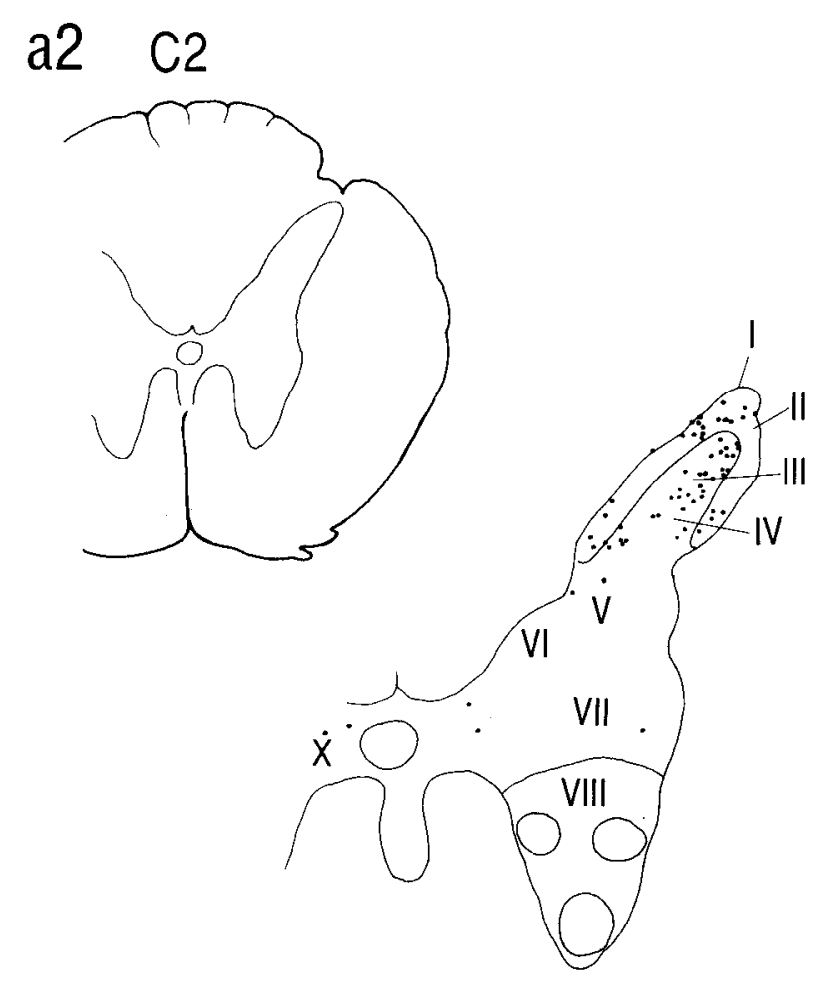

b1 C5

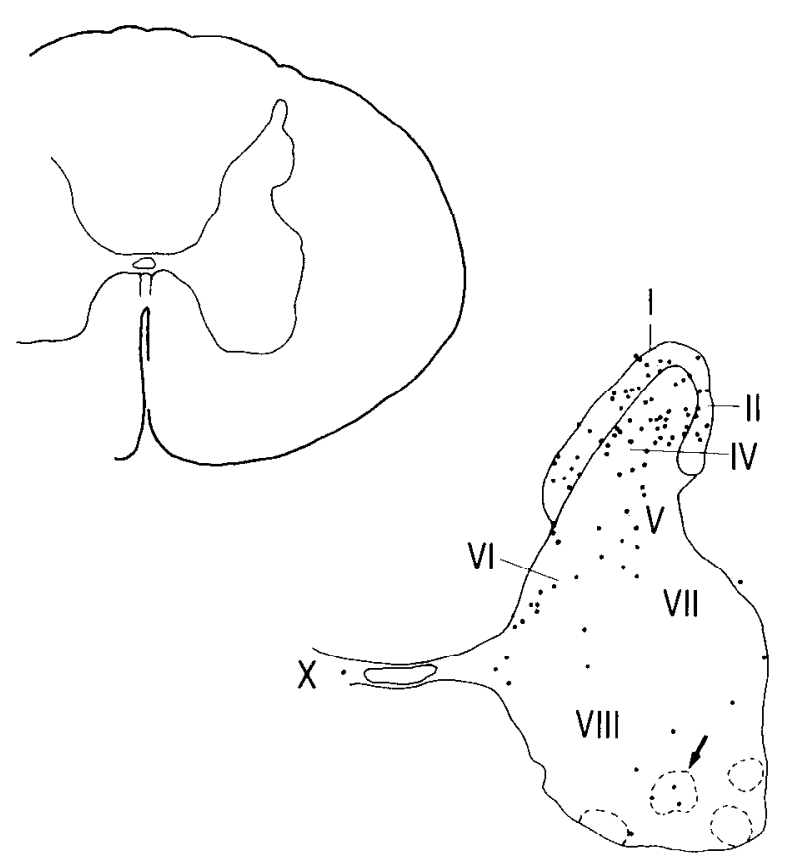

b2 $\mathrm{C} 5$

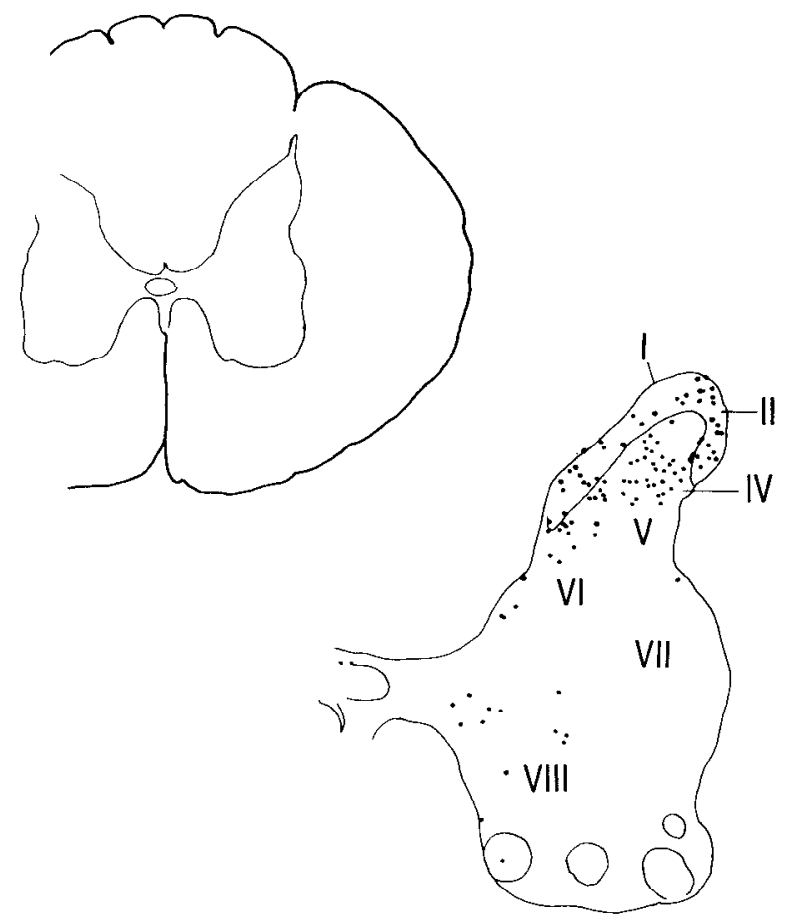



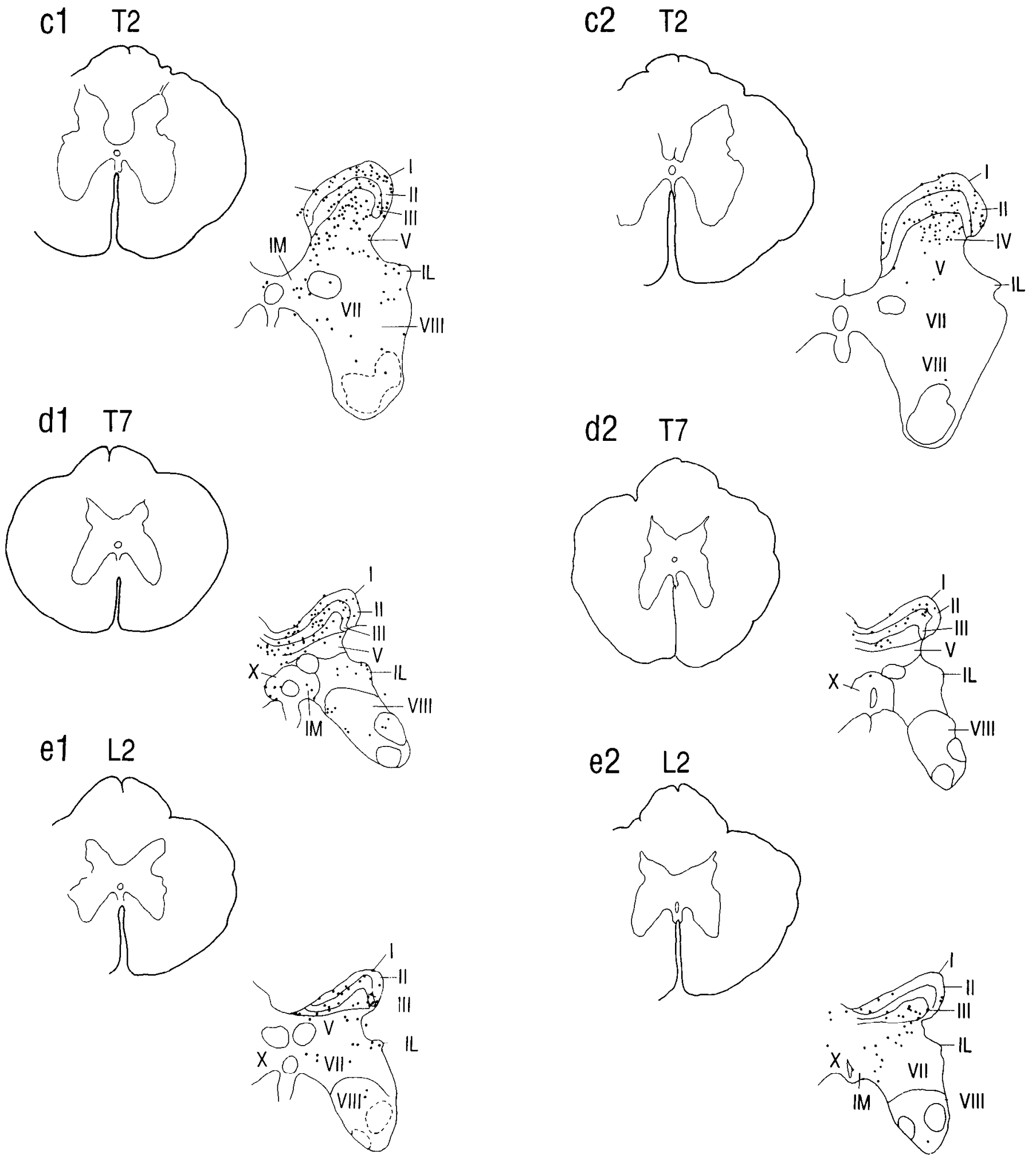

Figure 9. Continued.
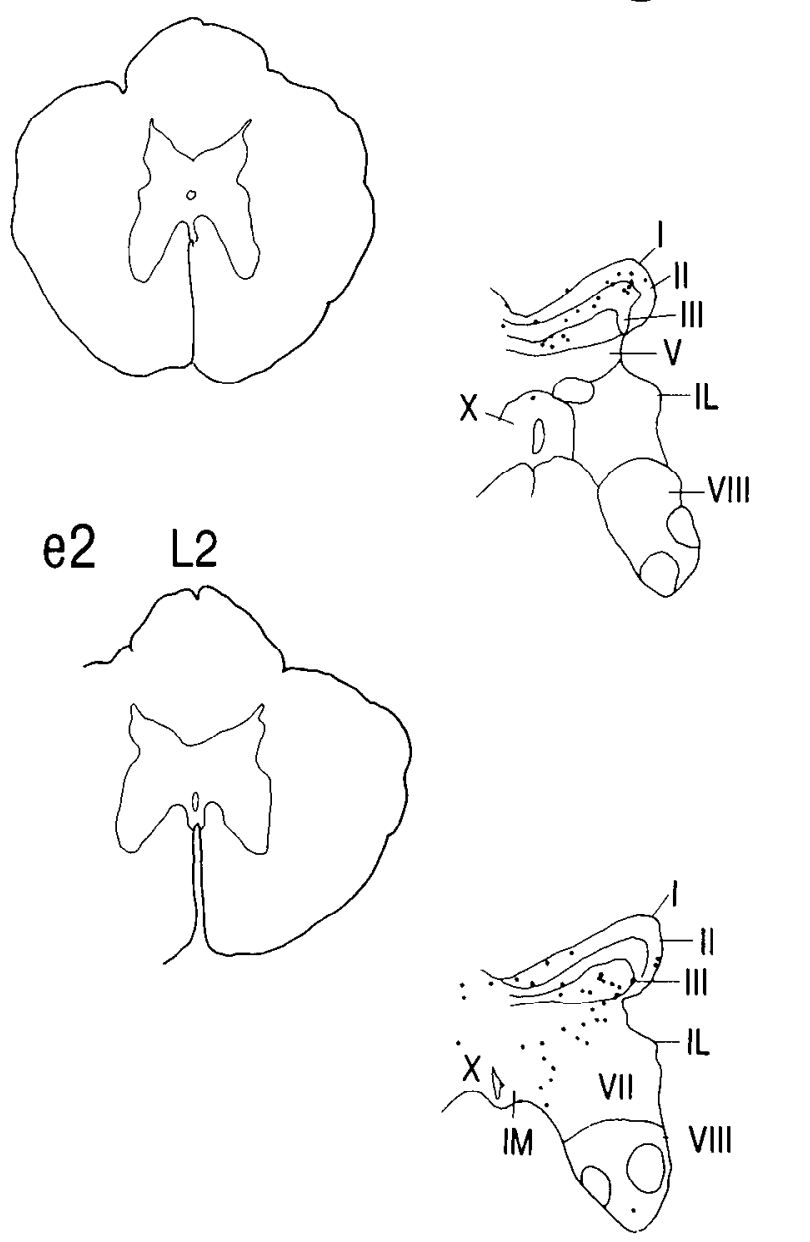

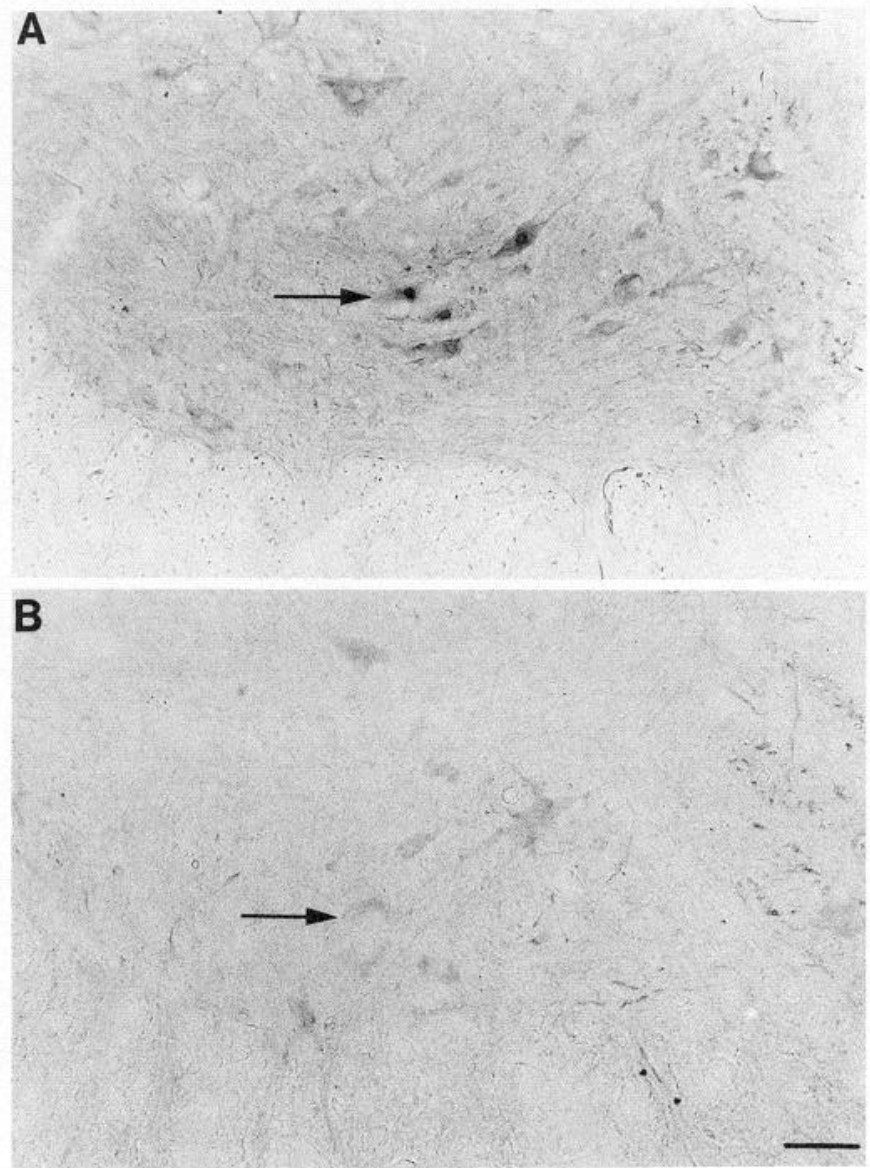

Figure 10. Photomicrographs of transverse sections of the fifth cervical segment demonstrating induction of FLI in nuclei of the phrenic motor nucleus (arrow) in an experimental animal $(A)$ and the absence of FLI in a control animal $(B)$. Scale bar, $100 \mu \mathrm{m}$.

nerve or intraduodenal injections of hypertonic saline (Boissonade et al., 1992).

Enhanced nuclear expression of FLI in drug-treated animals is also to be expected in association with activation of various prodromal symptoms of vomiting. For example, as discussed by Leslie and Reynolds (1992), immunolabeling in the dorsal vagal complex could also be associated with gastric stasis or conditioned taste aversion. In the reticular formation, FLI was expressed in distinct columns corresponding to the locations both of swallowing reflex interneurons located immediately subjacent to the NTS as well as dorsal to the nucleus ambiguus (Jean, 1990) and of the inferior salivatory nucleus in the dorsolateral reticular formation (Satomi et al., 1979).

Blood pressure changes associated with either a direct action of the emetic drugs and/or with emesis would account for enhanced FLI in the subretrofacial nucleus, which conveys sympathoexcitatory signals to spinal preganglionic motoneurons (Barman and Gebber, 1985; Dampney et al., 1987), and FLI in the intermediolateral cell column. One control decerebrate animal also exhibited enhanced labeling in the subretrofacial nucleus, probably in response to a drop in blood pressure. In contrast, the induction of the prominent arc of immunolabeled neurons in the intermediate reticular zone of the LTF would appear to be largely independent of changes in blood pressure.
Elevated arterial pressure in rabbits, in response to infusion of phenylephrine, is associated with enhanced FLI in the NTS, AP, and the caudal VLM (Li and Dampney, 1992), but not in columns of the LTF activated in association with emesis. Similarly, hemorrhage in cats induces FLI in the NTS and, in contrast to the aforementioned distribution, the subretrofacial nucleus and nucleus raphe pallidus, yet apparently sparse if any labeling of neurons in the LTF (McAllen et al., 1992).

Most of the emetic drugs have no effect on respiration at the doses used in this study. However, lobeline often causes a transient increase in respiratory discharge that could account for some of the FLI induced in respiratory-related regions in our experimental animals.

Other possible general sources of FLI in both experimental and control animals include stress and surgical procedures. Stress induced in rats by immobilization, noxious stimulation, or intraperitoneal injection of hypertonic salt solution induces FLI in the NTS and VLM as well as several other brain regions (Ceccatelli et al., 1989; Senba et al., 1993), but does not produce the extensive medullary distribution of FLI observed in our experimental animals. In addition, incision of the skin is sufficient to induce FLI in laminae I, II, V, and X of the spinal cord (Hunt et al., 1987). FLI was observed in these regions in both our control and experimental animals, although the labeling was enhanced in experimental animals in laminae II-III, $\mathrm{V}$, and VII.

The fact that almost indistinguishable patterns of FLI were observed following actual vomiting in an intact animal and fictive vomiting in decerebrate, paralyzed animals indicates that fluid depletion and electrolyte changes that can occur following prolonged vomiting (Dennis, 1983) were not important stimuli for producing Fos expression in our experimental animals. Decerebrate animals did, however, exhibit enhanced FLI in comparison to intact animals in the dorsal accessory olive, dorsal part of the medial and inferior vestibular nuclei, and raphe pallidus, presumably due to changes in the excitability of these regions following decerebration.

In confirmation of many previous studies, our findings provide additional evidence that c-fos expression can serve as a measure of functional activity. Indeed, the predicted patterns of nuclear expression in response to emesis were confirmed by our observations. However, one cannot exclude the possible involvement of additional brainstem regions in producing vomiting since Fos does not appear to be expressed following activation of some cells in the CNS, such as spinal motoneurons, dorsal column nuclei, and the substantia nigra (Hunt et al., 1987; Dragunow and Faull, 1989; Bullitt, 1990). Fos also may not be expressed by neurons that are reflexly inhibited, as suggested by the absence of FLI in the subretrofacial nucleus in response to baroreceptor activation ( $\mathrm{Li}$ and Dampney, 1992). This interpretation is reinforced by the markedly enhanced FLI expression in the same locus in response to hemorrhage, which, in contrast to baroreceptor activation, would have excited these sympathoexcitatory neurons (McAllen et al., 1992).

In the present study, the phrenic motor nucleus exhibited FLI in drug-treated animals but not in controls. This labeling in experimental animals probably reflects the fact that phrenic motoneurons are activated by different bulbospinal pathways during vomiting than during respiration (Bianchi and Grélot, 1989; Miller et al., 1990). The lack of FLI expression in phrenic motoneurons in response to central respiratory drive in our control animals may be related to evidence that Fos expression 
is transitory and that while a behavioral response may be elicited repeatedly, the continued induction of $c$-fos can be largely refractory (Morgan et al., 1987).

In the medullary reticular formation, neurons display unique distributions of FLI in response to different behavioral contexts, which further confirms the specificity of our findings. In our study, FLI was expressed by neurons concentrated in the intermediate reticular zone and subjacent tegmentum ncighboring the ventral medullary surface. Our experimental observations were reproducible and confirmed by consistent distributions of cells with enhanced intranuclear FLI expression as compared to control cases. Identical patterns were observed in the reticular formation following emesis in an intact animal and fictive vomiting in decerebrate, paralyzed animals. The topographic specificity of the immunostaining pattern was further confirmed by the absence of FLI in neurons along parallel bands intercalated between the intermediate zone and the spinal trigeminal complex. The FLI distribution following emesis was distinct from and more extensive than the patterns induced either by baroreceptor activation ( $\mathrm{Li}$ and Dampney, 1992) or unloading (hemorrhage) (McAllen et al., 1992) or in response to electrical stimulation of the pontine parabrachial nucleus (Krukoff et al., 1992). These data support the concept that the intermediate reticular zone of the LTF might constitute a distinct entity similar in organizational complexity to other cell groups in the lower brainstem (Holstege and Kuypers, 1977; Holstege et al., 1977; Reis and Ruggiero, 1991).

The neuronal substrate underlying the coordination of the vomiting response remains unclear. Previously proposed possible organizational schemes have included a localized "vomiting center" (Borison and Wang, 1949; Wang and Borison, 1951) or "pattern generator" (Fukuda and Koga, 1991) or, in contrast, more distributed control systems (Miller and Wilson, 1983; Davis et al., 1986a; Lawes, 1992). In the present study, no unique, well-defined group of neurons that might function as a "vomiting center" could be identified. Rather, the distribution of FLI suggests that neurons involved in coordinating emesis could be embedded in the cylindric arc of immunolabeled neurons that parcellates the intermediate reticular zone of the LTF. However, since the longitudinal columns that compose this arc extend from the spinomedullary junction into the pons, they can hardly be considered a tightly localized "center." In addition, it is important to determine which labeled LTF neurons merely represent activation of a cascade of higher-order neurons in response to emetics that excite vagal afferents or the AP and to what extent this immunolabeling is observed when vomiting is elicited by different stimuli, for example vestibular or psychogenic, that may engage other pathways. Furthermore, not all of the laheling observed in the LTF would be expected to specifically relate to the coordination of emesis since, for example, the LTF also contains neurons related to respiration (Vibert et al., 1976; King and Knox, 1984), cranial nerve integration (Holstege and Kuypers, 1977; Holstege et al., 1977), swallowing (Jean, 1990), and salivation (Satomi et al., 1979). However, our data corroborate the idea that vomiting is coordinated by a distributed control system rather than by a welldefined "center."

\section{References}

Barman SM, Gebber GL (1985) Axonal projection patterns of ventrolateral medullospinal sympathoexcitatory neurons. J Neurophysiol 53:1551-1566
Berman AI (1968) The brain stem of the cat. A cytoarchitectonic atlas with stereotaxic coordinates. Madison: University of Wisconsin.

Bianchi AL, Grélot L (1989) Converse motor output of inspiratory bulbospinal premotoneurones during vomiting. Neurosci Lett 104: 298-302.

Bianchi AL, Grélot L, Miller AD, King GL, eds (1992) Colloque INSERM, Vol 223, Mechanisms and control of emesis. Montrouge, France: Libbey.

Boissonade FM, Sharkey KA, Davison JS (1992) Fos expression in the ferret brainstem after emetic stimuli. Soc Neurosci Abstr 18:485.

Borison HL, Fairbanks VF (1952) Mechanism of veratrum-induced emesis in the cat. J Pharmacol Exp Ther 105:317-325.

Borison HL, Sampson SR (1961) The vagal body: receptor site for emetic action of veratrum alkaloids? Fed Proc 20:169.

Borison HI, Wang SC (1949) Functional localization of central coordinating mechanism for emesis in cat. J Neurophysiol 12:305-313.

Bullitt E (1990) Expression of c-fos-like protein as a marker for neuronal activity following noxious stimulation in the rat. J Comp Neurol 296:517-530

Carpenter DO (1989) Central nervous system mechanisms in deglutition and emesis. In: Handbook of physiology; The gastrointestinal system, Vol 1, Motility and circulation (Wood JD, ed), pp 685-714. Bethesda: American Physiological Society.

Ceccatelli S, Villar MJ, Goldstein M, Hökfelt T (1989) Expression of c-fos immunoreactivity in transmitter-characterized neurons after stress. Proc Natl Acad Sci USA 86:9569-9573.

Cohen DR, Curran T (1990) Analysis of dimerization and DNA binding functions in Fos and Jun by domain-swapping: involvement of residues outside the leucine zipper/basic region. Oncogene 5:929-939.

Costello DJ, Borison HL (1977) Naloxone antagonizes narcotic selfblockade of emesis in the cat. J Pharmacol Exp Ther 203:222-230.

Dampney RAL, Czachurski J, Dembowsky K, Goodchild $\Lambda$ K, Seller H (1987) Afferent connections and spinal projections of the pressor region in the rostral ventrolateral medulla of the cat. J Auton Nerv Syst 20:73-86.

Davis CJ, Harding RK, Leslie RA, Andrews PLR (1986a) The organisation of vomiting as a protective reflex. In: Nausea and vomiting: mechanisms and treatment (Davis CJ, Lake-Bakaar GV, GrahameSmith DB, eds), pp 65-75. Berlin: Springer.

Davis CJ, Lake-Bakaar GV, Grahame-Smith DG, eds (1986b) Nausea and vomiting: mechanisms and treatment. Berlin: Springer.

Dennis VW (1983) Fluid and electrolyte changes after vomiting. In: Antiemetics and cancer chemotherapy ( $\mathrm{T}$ aszlo $\mathrm{J}$, ed), pp 34-42. Baltimore: Williams \& Wilkins.

Dragunow M, Faull R (1989) The use of c-fos as a metabolic marker in neuronal pathway tracing. J Neurosci Methods 29:261-265.

Erickson JT, Millhorn DE (1991) Fos-like protein is induced in neurons of the medulla oblongata after stimulation of the carotid sinus nerve in awake and anesthetized rats. Brain Res 567:11-24.

Fukuda H, Koga T (1991) The Bötzinger complex as the pattern generator for retching and vomiting in the dog. Neurosci Res 12:471485.

Grélot L, Barillot JC, Bianchi AL (1990) Activity of respiratory-related oropharyngeal and laryngeal motoneurones during fictive vomiting in the decerebrate cat. Brain Res 513:101-105.

Gu Y, Gonzalez MF, Deutsch JA, Chen DY (1991) Expression of Fos in the rat brain following systemic injections of lithium chloride. Soc Neurosci Abstr 17:193.

Gwyn DG, Leslie RA, Hopkins DA (1979) Gastric afferents to the nucleus of the solitary tract in the cat. Neurosci Lett 14:13-17.

Holstege $G$ (1989) Anatomical study of the final common pathway for vocalization in the cat. J Comp Neurol 284:242-252.

Holstege G, Kuypers HGJM (1977) Propriobulbar fibre connections to the trigeminal, facial and hypoglossal motor nuclei. I. An anterograde degeneration study in the cat. Brain 100:239-264.

Holstege G, Tan J (1987) Supraspinal control of motoneurons innervating the striated muscles of the pelvic floor including urethral and anal sphincters in the cat. Brain 110:1323-1344.

Holstege G, Kuypers HGJM, Dekker JJ (1977) The organization of the bulbar fibre connections to the trigeminal, facial and hypoglossal motor nuclei. 11. An autoradiographic tracing study in the cat. Brain 100:265-286.

Hunt SP, Pini A, Evan G (1987) Induction of c-fos-like protein in spinal cord neurons following sensory stimulation. Nature 328:632634. 
Jean A (1990) Brainstem control of swallowing: localization and organization of the central pattern generator for swallowing. In: Neurophysiology of the jaws and teeth (Taylor A, ed), pp 294-321. London: Macmillan.

Kalia M, Mesulam M-M (1980) Brain stem projections of sensory and motor components of the vagus complex in the cat: II. Laryngeal, tracheobronchial, pulmonary, cardiac, and gastrointestinal branches. J Comp Neurol 193:467-508.

King GW (1980) Brain stem blood vessels and the organization of the lateral reticular formation in the medulla oblongata of the cat. Brain Res 191:253-259.

King GW, Knox CR (1984) Types and locations of respiratory-related neurons in lateral tegmental field of cat medulla oblongata. Brain Res 295:301-315.

Krukoff TI, Morton TI, Harris KM, Jhamandas JH (1992) Expression of c-fos protein in the rat brain elicited by electrical stimulation of the pontine parabrachial nucleus. J Neurosci 12:3582-3590.

Kucharczyk J, Stewart DJ, Miller AD, eds (1991) Nausea and vomiting: recent research and clinical advances. Boca Raton, FL: CRC.

Kumada M, Terui N, Kuwaki T (1990) Arterial baroreceptor reflex: its central and peripheral neural mechanisms. Prog Neurobiol 35 : 331-361.

Laffan RJ, Borison HL (1957) Emetic action of nicotine and lobeline J Pharmacol Exp 'Ther 121:468-476.

Lawes INC (1992) The central connections of area postrema define the paraventricular system involved in antinoxious behaviors. In: Nausea and vomiting: recent research and clinical advances (Kucharczyk J, Stewart DJ, Miller AD, eds), pp 77-101. Boca Raton, FL: CRC.

Leslie RA, Reynolds DJM (1992) Functional anatomy of the emetic circuitry in the brainstem. In: Colloque INSERM, Vol 223, Mechanisms and control of emesis (Bianchi $\Lambda \mathrm{L}$, Grélot L, Miller AD, King GL, eds), pp 19-27. Montrouge, France: Libbey.

Li Y-W, Dampney RAL (1992) Expression of c-fos protein in the medulla oblongata of conscious rabbits in response to baroreceptor activation. Neurosci Lett 144:70-74.

Loewy AD, Burton H (1978) Nuclei of the solitary tract: efferent projections to the lower brain stem and spinal cord in the cat. J Comp Neurol 181:421-450.

McAllen RM, Badoer E, Shafton AD, Oldfield BJ, McKinley MJ (1992) Hemorrhage induces $c$-fos immunoreactivity in spinally projecting neurons of cat subretrofacial nucleus. Brain Res 575:329-332.

McCarthy LE, Borison HL. (1984) Cisplatin-induced vomiting eliminated by ablation of the area postrema in cats. Cancer Treat Rep 68: 401-404.

Miller AD (1992) Physiology of brain stem emetic circuitry. In: Colloque INSERM, Vol 223, Mechanisms and control of emesis (Bianchi AL, Grélot L, Miller AD, King GL, eds), pp 41-50. Montrouge, France: Libbey.

Miller AD, Ezure K (1992) Behavior of inhibitory and excitatory propriobulbar respiratory neurons during fictive vomiting. Brain Res 578:168-176.

Miller AD, Nonaka S (1990a) Bötzinger expiratory neurons may inhibit phrenic motoneurons and medullary inspiratory neurons during vomiting. Brain Res 521:352-354.

Miller AD, Nonaka S (1990b) Mechanisms of abdominal muscle activation during vomiting. J Appl Physiol 69:21-25.

Miller AD, Nonaka S (1992) Mechanisms of vomiting induced by serotonin-3 receptor agonists in the cat: effect of vagotomy, splanchnicectomy or area postrema lesion. J Pharmacol Exp Ther 260:509517.

Miller AD, Ruggiero DA (1992) Emetic reflex arc revealed by expression of $\mathrm{c}$-fos protein in cats. Soc Neurosci Abstr 18:1276.

Miller AD, Wilson VJ (1983) 'Vomiting center' reanalyzed: an electrical stimulation study. Brain Res 270:154-158.

Miller AD, Tan LK, Suzuki 1 (198\%) Control of abdominal and expiratory intercostal muscle activity during vomiting: role of ventral respiratory group expiratory neurons. J Neurophysiol 57:1854-1866.

Miller AD, Nonaka S, Lakos SF, Tan LK (1990) Diaphragmatic and external intercostal muscle control during vomiting: behavior of inspiratory bulbospinal neurons. J Neurophysiol 63:31-36.

Morest DK (1967) Experimental study of the projections of the nucleus of the tractus solitarius and the area postrema in the cat. J Comp Neurol 130:277-299.

Morgan JI, Curran T (1989) Stimulus-transcription coupling in neurons: role of cellular immediate-early genes. Trends Neurosci 12:459_ 462.

Morgan JI, Curran T (1991) Stimulus-transcription coupling in the nervous system: involvement of the inducible proto-oncogenes fos and jun. Annu Rev Neurosci 14:421-451.

Morgan JI, Cohen DR, Hempstead JL, Curran T (1987) Mapping patterns of $\mathrm{c}-f \circ$ expression in the central nervous system after seizure. Science 237:192-197.

Naylor RJ, Rudd JA (1992) Mechanisms of chemotherapy-induced vomiting: involvement of 5- $\mathrm{HT}_{3}$ receptors. In: Colloque INSERM, Vol 223, Mechanisms and control of emesis (Bianchi AL, Grélot L, Miller AD, King GL, eds), pp 115-127. Montrouge, France: Libbey.

Nonaka S, Miller AD (1991) Behavior of upper cervical inspiratory neurons during fictive vomiting. J Neurophysiol 65:1492-1500.

Norgren R, Smith GP (1988) Central distribution of subdiaphragmatic vagal branches in the rat. J Comp Neurol 273:207-233.

Reis DJ, Ruggiero DA (1991) The bed nucleus of the transtegmental tract: a major autonomic integration center of the medulla oblongata. Soc Neurosci Abstr 16:11.

Rexed B (1954) A cytoarchitectonic atlas of the spinal cord in the cat. J Comp Neurol 100:297-379.

Reynolds DJM, Barber NA, Grahame-Smith DG, Leslie RA (1991) Cisplatin-evoked induction of $\mathrm{c}$-fos protein in the brainstem of the ferret: the effect of cervical vagotomy and the anti-emetic 5- $\mathrm{HT}_{3}$ receptor antagonist granisetron (BRL 43694). Brain Res 565:231236.

Rinaman L, Card JP, Schwaber JS, Miselis RR (1989) Ultrastructural demonstration of a gastric monosynaptic vagal circuit in the nucleus of the solitary tract in rat. $J$ Neurosci 9:1985-1996.

Sagar SM, Sharp FR, Curran T (1988) Expression of c-fos protein in brain: metabolic labeling at the cellular level. Science 240:1328-1331.

Satomi H, Yamamoto T, Isc H, Takahashi K (1979) Identification of the inferior salivatory nucleus in the cat as studied by HRP bathings of the transected glossopharyngeal nerve root. Neurosci Lett 11:259263

Senba E, Matsunaga K, Tohyama M, Noguchi K (1993) Stress-induced c-fos expression in the rat brain: activation mechanism of sympathetic pathway. Brain Res Bull 31:329-344.

Shapiro RE, Miselis RR (1985) The central neural connections of the area postrema in the rat. J Comp Neurol 234:344-364.

Sheng M, Greenberg ME (1990) The regulation and function of c-fos and other immediate early genes in the nervous system. Neuron 4:477485.

Taber E, Brodal A, Walberg (1960) The raphe nuclei of the brain stem in the cat. I. Normal topography and cytoarchitecture and general discussion. J Comp Neurol 114:161-187.

van der Kooy D, Koda LY (1983) Organization of the projections of a circumventricular organ: the area postrema in the rat. J Comp Neurol 219:328-338.

Vibert JF, Bertrand F, Denavit-Saubié M, Hugelin A (1976) Three dimensional representation of bulbo-pontine respiratory networks architecture from unity density maps. Brain Res 114:227-244.

Wan XST, Liang F, Moret V, Wiesendanger M, Rouiller EM (1992) Mapping of the motor pathways in rats: c-fos induction by intracortical microstimulation of the motor cortex correlated with efferent connectivity of the site of cortical stimulation. Neuroscience 49:749761 .

Wang SC, Borison HL (1951) The vomiting center: its destruction by radon implantation in dog medulla oblongata. Am J Physiol 166: 712-717.

Wang SC, Borison HL (1952) A new concept of organization of the central emetic mechanism: recent studies on the sites of action of apomorphine, copper sulfate and cardiac glycosides. Gastroenterology 22:1-12.

Zhang SP, Davis PJ, Carrive P, Bandler R (1992) Vocalization and marked pressor effect evoked from the region of the nucleus retroambigualis in the caudal ventrolateral medulla of the cat. Neurosci Lett 140:103-107. 